Document downloaded from:

http://hdl.handle.net/10251/115879

This paper must be cited as:

Requena-Peris, R.; Vargas, M.; Chiralt, A. (2018). Obtaining antimicrobial bilayer starch and polyester-blend films with carvacrol. Food Hydrocolloids. 83:118-133. doi:10.1016/j.foodhyd.2018.04.045

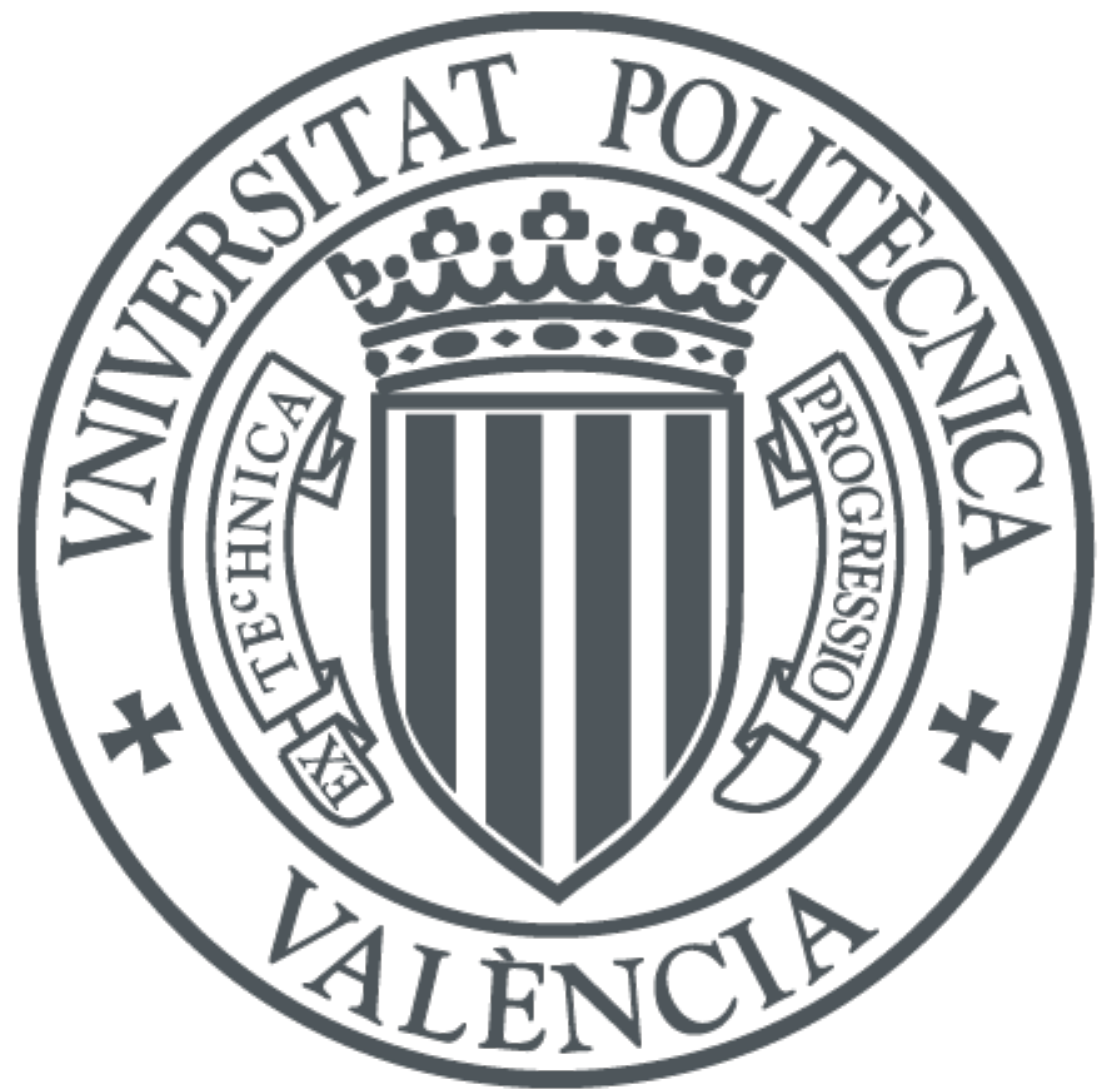

The final publication is available at

https://doi.org/10.1016/j.foodhyd.2018.04.045

Copyright Elsevier

Additional Information 


\title{
Obtaining antimicrobial bilayer starch and polyester-blend films with carvacrol
}

\author{
Raquel Requena*, María Vargas, Amparo Chiralt \\ Institute of Food Engineering for Development, Universitat Politècnica de València, Valencia, Spain
}

\section{A R T I C L E I N F O}

\section{Article history:}

Available online 2 May 2018

\section{Keywords:}

Starch

Polylactic acid

Polyhydroxybutyrate-co-hydroxyvalerate

Carvacrol

Packaging properties

Antibacterial properties

\begin{abstract}
A B S T R A C T
Bilayer films using polyester blends $(\mathrm{P})$ and starch $(\mathrm{S})$ were obtained and characterized, incorporating carvacrol as active compound. Carvacrol was incorporated by spraying it between melt blended and compression moulded sheets or through its incorporation into the chloroform P solution used to obtain P cast films. Different PLA-PHBV ratios (75:25 and 65:35) were tested, with and without 15 wt\% of PEG1000, whereas the 75:25 ratio with PEG was only used for cast sheets, based on its better overall properties. Mono and bilayers were characterized as to their tensile and water vapour barrier properties and thermal behaviour. Release kinetics of carvacrol in different food simulants and in in vitro antibacterial activity against Listeria innocua and Escherichia coli were also analysed. Incorporating carvacrol by spraying it between the polyester and starch sheets was not effective at retaining the compound in the bilayers. However, the incorporation of carvacrol into cast $\mathrm{P}$ films, and the subsequent formation of bilayers with the $\mathrm{S}$ sheets, was highly effective at providing practically total carvacrol retention. These active bilayers exhibited highly improved tensile and water vapour barrier capacity with respect to the $S$ monolayer (87\% reduction in WVP, $840 \%$ increase in elastic modulus) and inhibited the growth of L. innocua and E. coli from both P or S contact sides of bilayers, depending on the internal diffusion of carvacrol through the bilayer and its adequate release of the compound into the culture medium.
\end{abstract}

(C) 2018 Elsevier Ltd. All rights reserved.

\section{Introduction}

With society's growing concern for the environment and the great dependence on fossil fuels for plastic production, there is a need to find suitable environmentally-friendly solutions to the outbreak of plastic-based packaging. In this context, bio-based and biodegradable polymers such as polylactic acid (PLA) and polyhydroxyalkanoates (PHAs) have emerged as suitable green solutions (Avérous, 2004; Corre, Bruzaud, Audic, \& Grohens, 2012). The relatively widespread use of PLA on the market is due to its adequate physical properties, similar to polystyrene and poly(ethylene terephthalate) (Siracusa, Rocculi, Romani, \& Dalla Rosa, 2008), and its better features compared to other biopolymers, such as higher transparency, processability, printability and rate of composability (Arrieta et al., 2014b; Auras, Harte, \& Selke, 2004). However, PLA application in flexible films has been hindered due to its inherent brittle nature and its limited gas barrier properties (Mulle, González-Martínez, \& Chiralt, 2017b). Other biodegradable

\footnotetext{
* Corresponding author.

E-mail address: rarepe@upv.es (R. Requena).
}

polyester with good barrier capacity, such as polyhydroxybutyrateco-hydroxyvalerate (PHBV), have emerged, whose blend with PLA could improve the properties of the material. PHBV is an entirely biodegradable polyester synthesised by a wide variety of bacteria whose degree of crystallinity and melting point decrease as the hydroxyvalerate content increases (Savenkova, Gercberga, Bibers, \& Kalnin, 2000). Blending strategies between both polyesters and/or with plasticizers have recently been applied in order to obtain materials with different functionality, thus obtaining product blends with interesting physical, thermal and mechanical properties compared to the neat polymers (Armentano et al., b, 2015a,; Arrieta, López, Ferrándiz, \& Peltzer, 2013; Arrieta, Samper, López, \& Jiménez, 2014a; Arrieta et al., 2014b; Jost \& Kopitzky, 2015). Jost and Kopitzky (2015) reported a water vapour permeability reduction of $46 \%$ and a $40 \%$ lower oxygen permeability for a 75:25 PLPHBV ratio, compared to the pure PLA films. Arrieta et al. (2014a) and Armentano et al. (2015b) also highlighted the enhancement of the film barrier properties by combining PLA and polyhydroxybutyrate (PHB). Likewise, the addition of plasticizers, such as acetyl tributyl citrate, limonene, PEG300 and oligomer lactic acid, has been proposed as a means of improving the stretchability 
of both PLA and PHB films (Arrieta et al., 2013; Arrieta et al., 2014a; Armentano et al., b, 2015a).

Developing multilayer structures where materials with complementary properties are combined in the same sheet could also be an interesting approach to overcome the shortcomings of these promising polyesters (Martucci \& Ruseckaite, 2010). Starch, obtained from different natural resources, is a polymer which is widely available at low cost and provides biodegradable films with great oxygen barrier capacity (Ortega-Toro, Muñoz, Talens, \& Chiralt, 2016). Nevertheless, it is not more widely applied in the field of food packaging due to its high water sensitivity and water vapour permeability and its relatively low tensile strength (Acosta, Jiménez, Cháfer, González-Martínez, \& Chiralt, 2015; Souza, Goto, Mainardi, Coelho, \& Tadini, 2013; Versino, López, \& García, 2015). Combining PLA-PHBV blend films with starch films in bilayer structures could represent a good option to obtain materials with improved mechanical and barrier properties more suited to food packaging applications. Polyester layers would contribute to strengthening the bilayer while reducing water vapour permeability and the starch layer would help to control the oxygen and gas barrier capacity of the layer assembly. The multilayer strategy has usually been applied in synthetic plastic to obtain materials with better functionality, although there are few reported studies into biodegradable polymers. In this sense, PLA films have recently been combined in multilayer structures with MaterBi (commercial starch-based thermoplastic polymer) and sugar palm starch films (Sanyang, Sapuan, Jawaid, Ishak, \& Sahari, 2016; Scaffaro, Sutera, \& Botta, 2018); fish and bovine hide gelatin layers (Martucci \& Ruseckaite, 2010; Nilsuwan, Benjakul, \& Prodpran, 2017); soy protein films (González \& Igarzabal, 2013) and cassava starch films (Muller, González-Martínez, \& Chiralt, 2017a). The multilayer assemblies exhibited lower WVP and better mechanical performance than the hydrocolloid-based films, and better oxygen barrier capacity and film stretchability than neat PLA films. Likewise, the incorporation of active compounds, such as essential oils or their main constituents, could also provide added value to these polyester-starch bilayers (antimicrobial or antioxidant materials), since these natural and non-toxic compounds could inhibit the growth of foodborne bacteria and pathogenic microorganisms in the food packaging applications (Burt, 2004; Fratianni et al., 2010; Friedman, Henika, Levin, \& Mandrell, 2004). In this sense, numerous studies have shown that carvacrol (CA), the main compound of the Labiatae family, including Origanum, Satureja, Thymbra, Thymus, and Coridothymus (Babili et al., 2011; Xu, Zhou, Ji, Pei, \& Xu, 2008), exhibits a wide-spectrum antimicrobial activity (Requena, Vargas, Atarés, \& Chiralt, 2017a). Moreover, CA has been recognized as GRAS by the FDA and, therefore, approved as a safe food preservative in the USA and Europe.

The aim of this work was to obtain antimicrobial bilayer films with carvacrol, combining sheets of PLA-PHBV blends and thermoplastic starch, and characterize them as to their antimicrobial and functional properties and carvacrol release kinetics. PLA-PHBV blends were obtained by both melt blending and compression moulding or casting from their chloroform solutions. Two different strategies were used to incorporate carvacrol into bilayers: spraying the compound dose at the bilayer interface or incorporating it in the polyester-casting solution.

\section{Materials and methods}

\subsection{Materials and reagents}

Cassava starch, poly(3-hydroxybutyrate-co-3-hydroxyvalerate) (PHBV) 8\% and amorphous PLA 4060D with density of $1.24 \mathrm{~g} / \mathrm{cm}^{3}$, supplied respectively by Asia CO., LDT (Kalasin, Thailand),
NaturePlast (Caen, France) and Natureworks (U.S.A), were used to obtain bilayer films. The plasticizer poly(ethylene glycol) with molecular weight of $1000 \mathrm{~g} / \mathrm{mol}$ (PEG1000) was purchased from Sigma-Aldrich (Steinheim, Germany), whereas the glycerol was obtained from Panreac Química S.L.U. (Castellar del Vallés, Barcelona, Spain). Carvacrol (CA) and the different UV grade solvents, chloroform, methanol, ethanol, acetic acid and isooctane, were supplied by Sigma-Aldrich (Steinheim, Germany). Magnesium nitrate $\left(\mathrm{Mg}\left(\mathrm{NO}_{3}\right)_{2}\right)$, used to reach $53 \%$ relative humidity $(\mathrm{RH})$ during the film conditioning, was supplied by Vidra Foc S.A. (Barcelona, Spain).

For the antimicrobial activity analysis, stock cultures of Escherichia coli (CECT 101) and Listeria innocua (CECT 910) were supplied by the Spanish Type Culture Collection (CECT, Burjassot, Spain). Tryptone Soy Broth, Agar Bacteriological and Tryptone Phosphate Water were provided by Scharlab (Barcelona, Spain).

\subsection{Film preparation}

Thermo-processed polyester films were prepared by melt blending and compression-moulding using different PLA:PHBV ratios, and PEG1000 as plasticizer, in order to optimize the PLAPHBV ratio in the polyester blends, according to their functional properties. Afterwards, the best blend formulation was also obtained by casting incorporating or not $\mathrm{CA}$ in the film forming dispersion (FFD). Thus, these polyester monolayer films (compression moulded or cast) were combined with cassava starch (S) monolayer films to obtain polyester/starch bilayers, with or without CA.

\subsubsection{Preparation of polyester monolayer films by thermo- compression (T-PLA:PHBV:PEG)}

Pure PLA and PHBV films, as well as PLA-PHBV blend films were obtained at two different PHBV ratios (25 and $35 \mathrm{wt} \%$ ) in the polymer blend. In addition, PEG1000 was used as plasticizer in both pure and blend films in a constant proportion ( $15 \mathrm{~g} / 100 \mathrm{~g}$ polymer). Thus, the film components were melt-blended in a two-roll mill (Model LRM-M-100, Labtech Engineering, Thailand) at $200^{\circ} \mathrm{C}$ and $12 \mathrm{rpm}$ for $10 \mathrm{~min}$, except in the case of the pure PHBV formulation which was processed at $180^{\circ} \mathrm{C} .2 .5 \mathrm{~g}$ of the resulting pellets were compression moulded in a hydraulic press (Model LP20, Labtech Engineering, Thailand) in a three-step process. First, the steel sheets were pre-heated at $200^{\circ} \mathrm{C}$ for $5 \mathrm{~min}$. Then, the compression was performed at $200{ }^{\circ} \mathrm{C}$ and 100 bars for $4 \mathrm{~min}$, followed by a cooling cycle for $3 \mathrm{~min}$ until the temperature reached about $70^{\circ} \mathrm{C}$. The resulting films were stored at $53 \% \mathrm{RH}$ and $25^{\circ} \mathrm{C}$ until further analysis or their use to obtain bilayer films.

\subsubsection{Preparation of polyester monolayer films by casting \\ (C-75:25:15 and C-75:25:15-CA)}

PLA-PHBV blend monolayers were obtained by casting in a ratio of 75:25 with and without CA, using PEG 1000 ( $15 \mathrm{~g} / 100 \mathrm{~g}$ polymer) as a plasticizer, on the basis of results obtained from the thermoprocessed monolayers. The PLA, PHBV and PEG1000 blend was dissolved in chloroform at $5.88 \%(\mathrm{w} / \mathrm{w})$ by boiling under reflux for $4 \mathrm{~h}$. Then, the FFD was cooled until room temperature, adjusting the total weight with chloroform and incorporating, or not, the CA at $25 \mathrm{~g} \mathrm{CA} / 100 \mathrm{~g}$ polymer matrix (polyesters and plasticizer). The resulting FFDs were poured into $15 \mathrm{~cm}$ diameter Teflon plates ( $1.98 \mathrm{~g}$ solids per plate) and the solvent was evaporated overnight in a fume hood. When FFD contained CA, its content was $2.8 \mathrm{mg} \mathrm{CA} /$ $\mathrm{cm}^{2}$ of film, similar to that applied by spraying between layers using the processing method. The dried films were peeled off the casting surface and stored at $53 \% \mathrm{RH}$ and $25^{\circ} \mathrm{C}$ until further analysis or their use to obtain bilayer films. 
2.2.3. Preparation of starch monolayer films by compressionmoulding $(S)$

Cassava starch $(S)$ monolayer films were prepared with a S:water:glycerol:PEG1000 ratio of 100:55:30:0.5. Thermoplastic starch pellets were obtained in a two-roll mill (Model LRM-M-100, Labtech Engineering, Thailand) at $160^{\circ} \mathrm{C}$ and $12 \mathrm{rpm}$ for $20 \mathrm{~min}$. The resulting pellets were conditioned at $25^{\circ} \mathrm{C}$ and $53 \% \mathrm{RH}$ for 10 days, by using an oversaturated $\mathrm{Mg}\left(\mathrm{NO}_{3}\right)_{2}$ solution. $4 \mathrm{~g}$ of conditioned pellets were placed onto steel sheets and preheated in a hydraulic press (Model LP20, Labtech Engineering, Thailand) at $160{ }^{\circ} \mathrm{C}$ for $1 \mathrm{~min}$. Then, compression moulding was performed at the same temperature, applying 50 bars for $2 \mathrm{~min}$, followed by 100 bars for $6 \mathrm{~min}$. Finally, a cooling cycle was applied for $3 \mathrm{~min}$ until the temperature reached about $70^{\circ} \mathrm{C}$. The resulting films were stored at $53 \% \mathrm{RH}$ and $25{ }^{\circ} \mathrm{C}$ until further analysis or their use to obtain bilayer films.

\subsubsection{Preparation of active starch-polyester bilayer films}

(TP-S, TP-CA-S, CP-S, CP(CA)-S)

According to the best functional properties as packaging material, the T-75:25:15 film formulation was chosen among the different thermoprocessed polyester (TP) formulations to obtain bilayers with S films. To this end, CA was sprayed at the interface between both thermo-compressed films in the same ratio used in the cast polyester films $\left(2.8 \mathrm{mg} / \mathrm{cm}^{2}\right.$ of film). Then, both monolayers, with and without CA at the interface, were compression moulded in a hydraulic press (Model LP20, Labtech Engineering, Thailand) at $160^{\circ} \mathrm{C}$ and 100 bar for $2 \mathrm{~min}$ and cooled down until $80^{\circ} \mathrm{C}$ in $2 \mathrm{~min}$, thus obtaining TP-CA-S and TP-S films respectively, with a nominal mass fraction of TP film in the bilayers of about 0.38 .

Likewise, bilayer films were also obtained through thermocompression of both the $\mathrm{S}$ monolayer and the cast polyester monolayer $(\mathrm{CP})$ with and without $\mathrm{CA}$, thus obtaining $\mathrm{CP}(\mathrm{CA})-\mathrm{S}$ and CP-S films respectively, with a nominal mass fraction of $\mathrm{CP}$ film in the bilayers of about 0.33 .

\subsection{Film characterization}

\subsubsection{Analysis of the CA retention in the films}

CA distribution was analysed in newly prepared active films (TP$\mathrm{CA}-\mathrm{S}, \mathrm{CP}(\mathrm{CA})$ and $\mathrm{CP}(\mathrm{CA})-\mathrm{S})$, and others stored for 6 days, by methanol extraction and spectrophotometric quantification. Three different films were divided into four concentric circular sections: internal circles of $3 \mathrm{~cm}$ radius and circular crowns of internalexternal radii of $3-5,5-7$ and $7-7.5 \mathrm{~cm}$. Film samples $(0.2 \mathrm{~g})$ of each section were kept in $\mathrm{P}_{2} \mathrm{O}_{5}(0 \% \mathrm{HR})$ for $24 \mathrm{~h}$ and extracted in $10 \mathrm{~mL}$ of methanol under constant stirring for $72 \mathrm{~h}$ at $20^{\circ} \mathrm{C}$. The methanol extracts were filtered, properly diluted and their absorbance was measured using UV-visible spectrophotometer (Thermo Scientific Evolution 201, EEUU) at 275 (maximum of absorption of the CA in methanol), using as the blank solution the methanol extract of the corresponding control film without CA in each case. The absorbance measurements were transformed into CA concentration values ( $\mathrm{g} \mathrm{CA} / 100 \mathrm{~g}$ film) using the corresponding calibration curve. All measurements were taken in triplicate.

\subsubsection{Thermal behaviour}

Differential scanning calorimetry (DSC) analyses were performed using a DSC (Stare System, Mettler Toledo Inc., Switzerland). Film samples (about $10 \mathrm{mg}$ ) were placed into aluminium pans (Seiko Instruments, P/N SSC000C008) and analysed using a multiple scan. Firstly, samples were heated from room temperature to $180^{\circ} \mathrm{C}$ at $10^{\circ} \mathrm{C} / \mathrm{min}$. Then, samples were cooled to $-30^{\circ} \mathrm{C}$ at $-50^{\circ} \mathrm{C} /$ min and heated again to $180^{\circ} \mathrm{C}$ at $10^{\circ} \mathrm{C} / \mathrm{min}$. All measurements were taken in duplicate under a nitrogen stream of $20 \mathrm{~mL} / \mathrm{min}$.
A thermogravimetric analyser (TGA/SDTA 851e, Mettler Toledo, Schwarzenbach, Switzerland) was used to determine the thermal stability of the different film formulations. Measurements of the thermal weight loss of each type of film were taken in duplicate in a temperature range between 25 and $600^{\circ} \mathrm{C}$ at $10^{\circ} \mathrm{C} / \mathrm{min}$ under a nitrogen stream of $20 \mathrm{~mL} / \mathrm{min}$.

\subsubsection{Tensile properties}

The tensile behaviour of the films was determined following the ASTM D882 standard method by using a texture analyser (TAXTplus, Stable Micro Systems, Surrey, United Kingdom). A handheld digital micrometer (Electronic Digital Micrometer, Comecta S.A., Barcelona, Spain) was used to measure film thickness to the closest $0.001 \mathrm{~mm}$, at six random positions around the film. Then, film strips ( $25 \mathrm{~mm}$ wide, $100 \mathrm{~mm}$ long) were mounted in the tensile grips ( $5 \mathrm{~mm}$ of film between grips) and stretched at $50 \mathrm{~mm} / \mathrm{min}$ until breaking. The elastic modulus (EM), tensile strength at break (TS) and percentage of elongation at break (E) were obtained from stress-strain curves. Measurements (eight replicates per formulation) were taken in films conditioned at $25{ }^{\circ} \mathrm{C}$ and $53 \% \mathrm{RH}$ for one week.

\subsubsection{Water vapour permeability}

The water vapour permeability (WVP) of the films was determined according to the ASTM E-96-95 gravimetric method. Round film samples ( $35 \mathrm{~mm}$ diameter) of each formulation were placed on Payne permeability cups $(3.5 \mathrm{~cm}$ in diameter, Elcometer SPRL, Hermelle/s Argenteau, Belgium) at $25^{\circ} \mathrm{C}$ and a $53-100 \% \mathrm{RH}$ gradient, which was created with an oversaturated $\mathrm{Mg}\left(\mathrm{NO}_{3}\right)_{2}$ solution and distilled water, respectively. In order to reduce the resistance to transport of water vapour, a fan was placed above each cup. The cups were weighed periodically using an analytical balance $( \pm 0.00001 \mathrm{~g})$, until the steady state was reached and the WVP was calculated from the slope of the curves of weight loss versus time. Measurements (in quadruplicate per formulation) were taken in films conditioned for 1 week at $25^{\circ} \mathrm{C}$ and $53 \% \mathrm{RH}$.

\subsubsection{Release kinetics of $C A$ in food simulants}

The release kinetic study was carried out only for the $\mathrm{CP}(\mathrm{CA})$ monolayer and the $\mathrm{CP}(\mathrm{CA})-\mathrm{S}$ bilayer films due to the poor $\mathrm{CA}$ retention obtained for the TP-CA-S bilayer films. The release kinetics of CA from these films was studied in four different food simulants according to the Commission regulation (EU) 2015/174 amending and correcting Regulation (EU) No 10/2011 on plastic materials and articles intended to come into contact with food. Thus, aqueous food with neutral and acid $\mathrm{pH}$ were simulated with $10 \%$ ethanol $(\mathrm{v} / \mathrm{v})(\mathrm{A})$ and $3 \%$ acetic acid (w/v) (B), respectively, whereas fatty foods were simulated with $50 \%$ ethanol (v/v) (D1) and isooctane (D2). Film samples of $500 \mathrm{mg}$ were placed in contact with $100 \mathrm{~mL}$ of each simulant and kept under stirring at $20^{\circ} \mathrm{C}$ throughout the time. The absorbance of the different solutions was measured at different contact times up to equilibrium, thus obtaining the CA profile concentration in each simulant over time using standard calibration curves previously obtained in each simulant. All analyses were performed in triplicate and the corresponding extracts of films without CA were used as blank solutions for the absorbance measurements, for each simulant and time.

The CA amount released into the simulants at each time $\left(\mathrm{M}_{\mathrm{t}}\right)$ was fitted to Peleg's model (Eq. (1) (Peleg, 1988), and the constants $\mathrm{k}_{1}$ (inversely related to the initial release rate) and $\mathrm{k}_{2}$ (related to the asymptotic release value) were determined. The amount of active released at equilibrium $\left(\mathrm{M}_{\infty}\right)$ was calculated from $\mathrm{k}_{2}$ (Eq. (2). 
Table 1

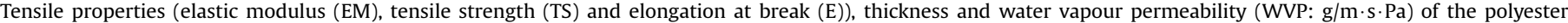
monolayers obtained by thermo-compression $(T)$ and casting $(C)$ with different PLA:PHBV:PEG ratios. Mean values \pm standard deviations.

\begin{tabular}{|c|c|c|c|c|c|}
\hline Formulation & $\mathrm{EM}(\mathrm{MPa})$ & TS (MPa) & $\mathrm{E}(\%)$ & Thickness $(\mu \mathrm{m})$ & $\operatorname{WVP}\left(\mathrm{x} 10^{-12}\right)$ \\
\hline $\mathrm{T}-100: 0: 0$ & $1670 \pm 70^{\mathrm{b}}$ & $49 \pm 2^{\mathrm{a}}$ & $3.2 \pm 0.1^{d}$ & $124 \pm 8^{b}$ & $3.3 \pm 0.3^{d}$ \\
\hline T-100:0:15 & $570 \pm 90^{\mathrm{e}}$ & $17 \pm 1^{\mathrm{e}}$ & $57.2 \pm 5.5^{\mathrm{b}}$ & $107 \pm 4^{f}$ & $5.4 \pm 0.4^{c}$ \\
\hline T-0:100:0 & $1760 \pm 50^{a}$ & $33 \pm 2^{b}$ & $2.6 \pm 0.3^{\mathrm{de}}$ & $131 \pm 8^{a}$ & $1.2 \pm 0.4^{\mathrm{e}}$ \\
\hline T-0:100:15 & $1300 \pm 40^{d}$ & $28 \pm 2^{c}$ & $3.7 \pm 0.4^{\mathrm{d}}$ & $109 \pm 7^{f}$ & $3.6 \pm 1.4^{\mathrm{d}}$ \\
\hline T-65:35:0 & $1490 \pm 40^{c}$ & $32 \pm 1^{b}$ & $2.2 \pm 0.1^{\mathrm{de}}$ & $120 \pm 5^{d}$ & $1.8 \pm 0.1^{\mathrm{e}}$ \\
\hline T-65:35:15 & $510 \pm 40^{\mathrm{ef}}$ & $4 \pm 1^{g}$ & $0.8 \pm 0.3^{\mathrm{e}}$ & $124 \pm 8^{b}$ & $9.1 \pm 1.8^{\mathrm{b}}$ \\
\hline $\mathrm{T}-75: 25: 0$ & $1470 \pm 30^{c}$ & $31 \pm 2^{b}$ & $2.2 \pm 0.2^{\mathrm{de}}$ & $126 \pm 2^{b}$ & $3.1 \pm 0.1^{\mathrm{d}}$ \\
\hline $\mathrm{T}-75: 25: 15$ & $460 \pm 40^{\mathrm{f}}$ & $9 \pm 1^{\mathrm{f}}$ & $7.1 \pm 1.8^{\mathrm{c}}$ & $116 \pm 9^{\mathrm{e}}$ & $4.2 \pm 0.3^{\mathrm{cd}}$ \\
\hline$C-75: 25: 15$ & $1270 \pm 20^{d}$ & $22 \pm 1^{d}$ & $2.1 \pm 0.2^{\mathrm{de}}$ & $116 \pm 5^{e}$ & $11.9 \pm 0.6^{\mathrm{a}}$ \\
\hline C-75:25:15-CA & $520 \pm 80^{e f}$ & $21 \pm 2^{\mathrm{d}}$ & $130.1 \pm 1.9^{a}$ & $141 \pm 9^{a}$ & $9.6 \pm 1.2^{\mathrm{b}}$ \\
\hline
\end{tabular}

a-f: Different superscripts within the same column indicate significant differences among film samples $(p<0.05)$.

$\frac{t}{M_{t}}=k_{1}+k_{2} \cdot t$

$M_{\infty}=\frac{1}{k_{2}}$

Fick's second law was fitted to the experimental data to obtain the diffusion coefficient of CA from the films towards the food simulants. Film samples were considered as infinite plane sheets with the half thickness as the characteristic dimension, where the active compound diffuses only in an axial direction. The diffusional long-time equation with ten terms for an infinite plane sheet (Crank, 1975) was used to determine the diffusion coefficient (D) values of CA for the different solvents (Eq. (3)), where $M_{t}$ is the mass of compound released at time $t, \mathrm{M}_{\infty}$ is the mass of compound released at equilibrium and $\mathrm{L}$ is the half thickness of film. The Solver tool (Microsoft Excel $2013^{\circledR}$ ) was used to optimize the D values, by minimizing the Sum of Squared Errors (SSE), considering the following boundary conditions:

$$
\begin{aligned}
& t=0 \quad 0<x<L \quad c=c_{0} \\
& t>0 \quad x=0 \quad x=L \quad c=0 \\
& M_{t}=M_{\infty}\left(\frac{8}{\pi^{2}} \sum_{n=0}^{\infty}\left[\frac{1}{(2 n+1)^{2}} \exp \left\{\frac{-\pi^{2} D(2 n+1)^{2} t}{L^{2}}\right\}\right]\right)
\end{aligned}
$$

\subsubsection{Antibacterial activity assessment}

Listeria innocua (CECT 910) and Escherichia coli (CECT 101) were regenerated (from a culture stored at $-25^{\circ} \mathrm{C}$ with $30 \%$ glycerol) by transferring an aliquot into $10 \mathrm{~mL}$ of TSB and incubating at $37^{\circ} \mathrm{C}$ for $24 \mathrm{~h}$. A $10 \mu \mathrm{L}$ aliquot was transferred from this culture into $10 \mathrm{~mL}$ of TSB and grown again at $37^{\circ} \mathrm{C}$ for $24 \mathrm{~h}$, thus obtaining a culture in the stage of exponential growth. Petri dishes with $10 \mathrm{~g}$ of TSA were properly inoculated to obtain an inoculum concentration of $10^{4} \mathrm{CFU} / \mathrm{g}$. Circular samples of $55 \mathrm{~mm}$ in diameter, obtained from the different kinds of films, were placed on inoculated TSA plates and incubated for 6 days at $10^{\circ} \mathrm{C}$. Then, the microbial counts were examined by serial dilutions and plating technique with TSA incubated for $24 \mathrm{~h}$ at $37^{\circ} \mathrm{C}$. All tests were performed in duplicate and the corresponding films without CA were used as control samples. In the case of the bilayer films, the antimicrobial test was carried out on both sides of the films, by placing each one in contact with the culture media. Thus, the microbial counts were reported for both analyses: the polyester layer or the $S$ layer in contact with the culture media.

\subsubsection{Statistical analyses}

Statistical analysis of variance with Fisher's least significant difference at 95\% confidence level was performed using Statgraphics Centurion XVI (Manugistics Corp., Rockville, MD, USA).

\section{Results}

\subsection{Properties of the polyester blend monolayer films}

\subsubsection{Physical properties}

Table 1 includes the tensile properties (elastic modulus (EM), tensile strength (TS) and elongation at break (E)) of the polyester monolayers obtained by thermo-compression (T) or casting (C) with different PLA:PHBV:PEG ratios. Neat PLA and PHBV films were highly resistant and stiff, with values of tensile parameters in the range of those previously reported by other authors (Chen, Hao, Guo, Song, \& Zhang, 2002; Courgneau et al., 2012; Muller et al., 2017a). The incorporation of 15\% of PEG significantly increased the PLA film stretchability, which was twenty times higher than that of the neat PLA film, coherent with the decrease in the glass transition temperature (commented on below) and the subsequent increase in the polymer chain mobility, as also observed by Sheth, Kumar, Davé, Gross, and McCarthy (1997). On the other hand, the addition of PHBV (25 or 35\%) to PLA films led to less resistant materials than pure PLA films, with low stretchability values. This can be attributed to the lack of total polymer miscibility which led to discontinuities in the PLA network, including PHBV domains, which favoured the film break (Gérard, Budtova, Podshivalov, \& Bronnikov, 2014). When PHBV was included in the PEGplasticized PLA matrix, a significant reduction in both the film stretchability and resistance was observed. This effect was more pronounced for the highest proportion of PHBV, which gave rise to an extremely brittle material. However, the T-75:25:15 formulation showed global mechanical properties that could meet some food packaging requirements. Therefore, this thermo-processed monolayer formulation was selected to obtain active bilayer films with $\mathrm{S}$ sheets and CA sprayed at the interface. This ratio was also used to obtain polyester monolayer films by casting with and without CA, whose tensile properties are also summarized in Table 1.

No significant differences were observed in the thickness of monolayers obtained by the different methods, since a similar surface solid density was used in both cases. However, the film formation processes significantly affected the mechanical behaviour of the polyester blend films. Cast polyester blend films (C75:25:15) were more resistant, stiffer and less extensible than those obtained by compression moulding. As reported by Fakhouri et al. (2013) and Moreno, Díaz, Atarés, and Chiralt (2016), during the solvent evaporation in the casting process, the polymer chains can interact more effectively than during melt blending, thus giving 
rise to more compact matrices. Incorporating $C A$ into cast polyester films (C-75:25:15-CA) significantly reduced the EM and enhanced stretchability due to the random distribution of the CA molecules between the polymer chains, which increases their free volume, provoking a plasticizing effect and reducing the matrix strength. The plasticizing effect of CA in different polymer matrices has also been reported in neat PHBV films (Requena, Jiménez, Vargas, \& Chiralt, 2016a), polypropylene (Ramos, Jiménez, Peltzer, \& Garrigós, 2012), alginate-apple puree (Rojas-Graü et al., 2007) or Gelidium Corneum films (Lim, Hong, \& Song, 2010).

As Jost and Kopitzky (2015) reported, pure PLA films showed significantly higher WVP values than PHBV films (Table 1). The water vapour barrier capacity of PLA and PHBV films decreased when $15 \%$ of PEG was included in the film formulation due to the polymer matrix rearrangement that results in higher free volume which facilitates molecular diffusion (Byun, Kim, \& Whiteside, 2010). The incorporation of PHBV into PLA matrices enhanced water vapour barrier capacity of the films, which was significantly notable with $35 \%$ PHBV, when a reduction in the WVP of $50 \%$ was obtained. As occurred in the pure polymer films, PEG addition to PLA-PHBV blends enhanced the film WVP, in line with its plasticizing effect and the subsequent promotion of molecular mobility and diffusion. However, in PEG-plasticized blends, samples with the highest PHBV content exhibited higher WVP values than those of the sample with the lowest PHBV content. This suggests different PEG interactions with both polymers in the blend, giving rise to a non-equivalent partition of the plasticizer between PLA and PHVB domains. In fact, the plasticizing effect of PEG on pure PLA matrices was much more effective than on PHBV films (commented on below). The increase in the PHBV ratio in the blend would imply a greater amount of PEG available for the PLA domains, thus provoking greater molecular mobility in these regions of the film, which enhanced water diffusion through the PLA phase.

Polyester monolayers obtained by casting had worse water vapour barrier capacity than the corresponding monolayers obtained by thermo-processing, contrary to what is expected from the effect observed on the tensile properties, which suggested a more compact polymer arrangement in the matrix with better cohesion forces (Table 1). In this sense, the different degree of crystallinity of the polymers in the matrix could play an important role in both the tensile behaviour and barrier capacity of the films. The addition of CA significantly improved the water vapour barrier capacity, in line with the enhancement of the hydrophobic nature of the matrix, thus limiting the solubility of the water molecules (Benavides, Villalobos-Carvajal, \& Reyes, 2012; Requena et al., 2016a; Woranuch \& Yoksan, 2013). The effect of CA on polymer crystallization could also affect both the tensile and barrier properties of the films.

\subsubsection{Thermal behaviour}

The DSC analyses were carried out in order to determine the blending compound effects on the glass transition $\left(\mathrm{T}_{\mathrm{g}}\right)$, crystallization $\left(\mathrm{T}_{\mathrm{c}}\right)$ and melting $\left(\mathrm{T}_{\mathrm{m}}\right)$ processes of the PLA-PHBV-based monolayers. Fig. 1 shows the thermograms of the different polyester monolayers obtained by both thermo-compression and

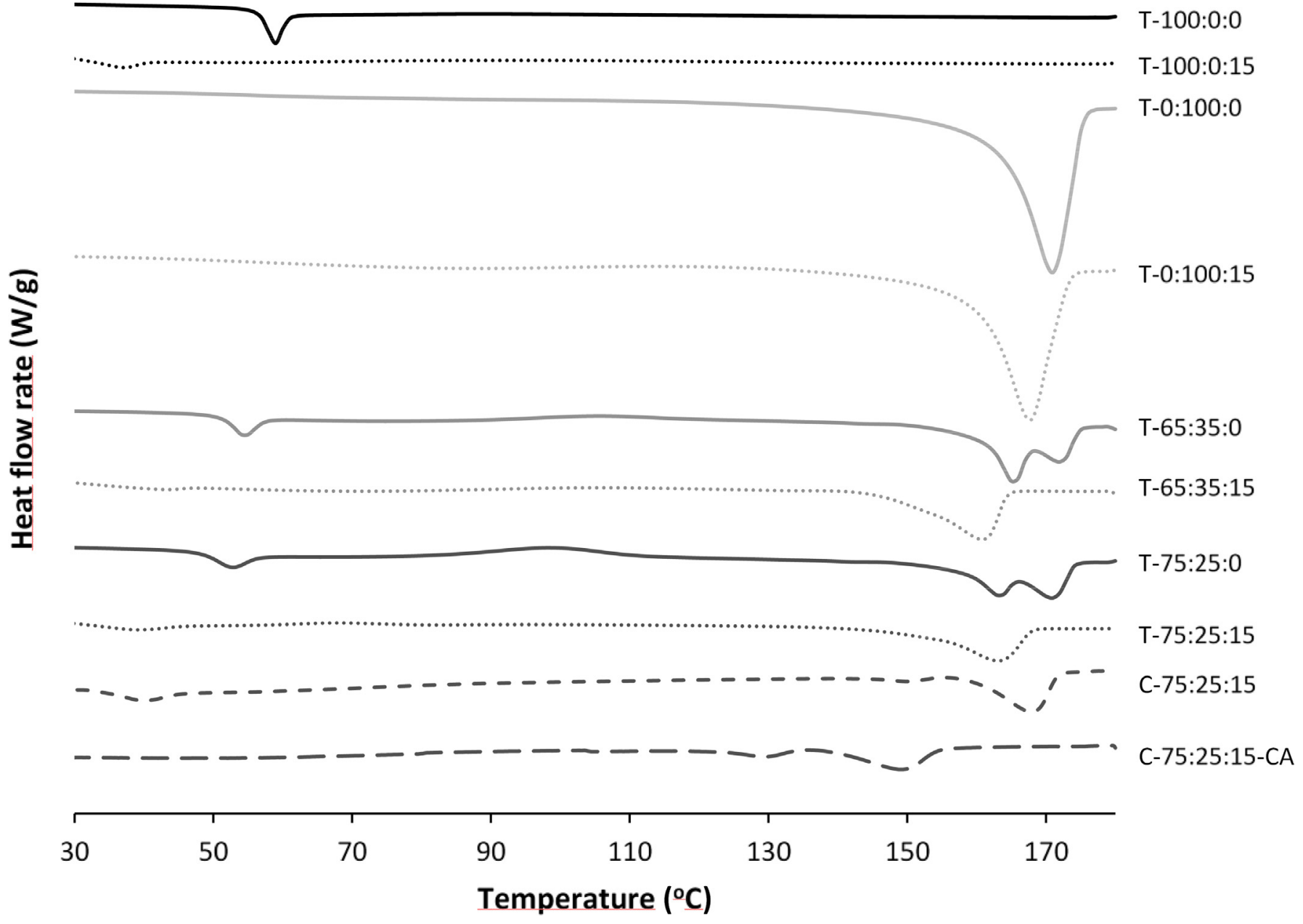

Fig. 1. DSC thermograms of the polyester monolayers obtained by thermo-compression (T) and casting (C) at different PLA:PHBV:PEG ratios from the first heating scan. 
casting in the first heating scan. The PLA monolayers, both with and without PEG, only exhibited glass transition, in line with their amorphous nature. However, for the PHBV films, with and without plasticizer, only the melting of the crystalline polymer fraction was observed. There was no PEG crystallization in either the PLA or PHBV films, since the corresponding melting peak, at around $35^{\circ} \mathrm{C}$, was not observed (Requena et al., 2016a). This suggests that PEG was interacting strongly in the matrix, without phase separation, thus inhibiting its crystallization. Likewise, monolayers containing PLA-PHBV blends exhibited PLA glass transition and PHVB melting, although an exothermic crystallization could be observed at around $100{ }^{\circ} \mathrm{C}$ during the heating scan $(\Delta \mathrm{Hc}: 10.5 \pm 0,3$ and $4.7 \pm 0,3 \mathrm{~J} / \mathrm{g}$ PLA for blends containing 25 and 35\% PHBV, respectively). This must be attributed to the PLA recrystallization, as reported by Muller et al. (2017a) and Armentano et al. (2015a,b), since two melting peaks were observed in these cases with peak temperatures near to those of the PLA and PHBV, respectively. This indicates that the PHBV promotes the PLA crystallization during heating after its glass transition (Arrieta et al., 2014a; Zhang \& Thomas, 2011), due to its ability to act as a nucleating agent (Furukawa et al., 2005). In the multi-step melting process, the peak at a lower temperature (about $160^{\circ} \mathrm{C}$ ) was attributed to the crystallized PLA ( $\mathrm{T}_{\mathrm{m} \text { PLA }}$ ), and the peak at a higher temperature (about $170^{\circ} \mathrm{C}$ ), was attributed to the crystallized PHBV ( $\mathrm{T}_{\mathrm{m} \text { PHBV }}$ ). This behaviour agrees with the lack of total miscibility between both polymers, as reported by Armentano et al. (2015a, b) and the nucleating effect of PHBV (Furukawa et al., 2005).

Table 2 shows the thermal parameters from the first and second heating scans, where the previous thermal history of the samples has been deleted, as well as the crystallization temperatures $\left(T_{c}\right)$ obtained from the cooling step for the different polyester monolayers, obtained by both thermo-compression and casting. During the cooling steps, only one crystallization peak was observed at the applied cooling rate $\left(50^{\circ} \mathrm{C} / \mathrm{min}\right)$. The addition of PEG to the PLA films exerted a strong plasticizing effect, thus bringing down its $\mathrm{T}_{\mathrm{g}}$ from $57^{\circ} \mathrm{C}$ to $39^{\circ} \mathrm{C}$, whereas adding it to PHBV films led to less crystalline materials, since the plasticizer decreased the crystallization and melting enthalpies $\left(\Delta \mathrm{H}_{\mathrm{m}}\right.$ and $\left.\Delta \mathrm{H}_{\mathrm{c}}\right)$, as well as the $\mathrm{T}_{\mathrm{m}}$ and $\mathrm{T}_{\mathrm{c}}$ values, as previously reported by Requena, Jímenez, Vargas, \& Chiralt (2016b). The $\mathrm{T}_{\mathrm{g}}$ corresponding to the PHBV amorphous phase, expected at around $-1{ }^{\circ} \mathrm{C}$ according to some authors (Ferreira, Zavaglia, \& Duek, 2002; Martelli et al., 2012), could not be evaluated with the used heating rate as reported (Gerard \& Budtova, 2012). In addition to the nucleating PHBV effect on the PLA crystallization, PHBV led to a significant shift in the $T_{g}$ of PLA to lower temperatures in PLA-PHBV blends, which suggests a partial miscibility of both polyesters. Conversely, PLA inhibited the PHBV crystallization, thus reducing both the $\Delta \mathrm{H}_{\mathrm{m}}$ and $\Delta \mathrm{H}_{\mathrm{c}}$ values of PHBV. No PLA recrystallization, or subsequent separated melting, was observed during the first heating scan when films contained PEG (Fig. 1), although the observed melting temperature was lower than that obtained for pure PHBV or PEG-plasticized PHBV, which could indicate the co-crystallization of both polymers to some extent. Both polyester blend films showed lower PLA $T_{g}$ values when they contained PEG, thus demonstrating its plasticizing effect, which was more noticeable for the PLA:PHBV ratio of 65:35. This suggests that a major proportion of PEG was in the PLA phase when the PHBV ratio increased, thus enhancing its plasticization, as could be deduced from the film water vapour barrier properties, commented on above. However, the extensibility of this PEGplasticized film with a higher proportion of PHBV was much more limited, probably due to the more dispersed phase of PHBV, which promoted film fracture.

The polyester blend monolayer obtained by casting (C-75:25:15) exhibited a similar thermal behaviour to the corresponding thermoprocessed formulation, but no PLA crystallization was clearly detected during the first heating scan. However, two separate melting peaks were observed corresponding to each polymer

Table 2

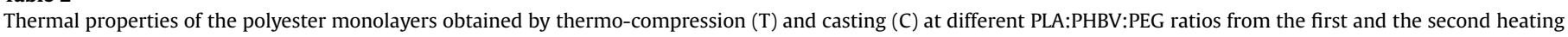

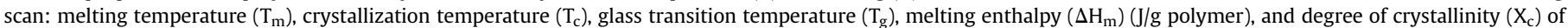
each polymer considering the separate integration of each melting endotherm and the polymer mass fraction in the blend. Mean values \pm standard deviation.

\begin{tabular}{|c|c|c|c|c|c|c|c|}
\hline Formulation & $\mathrm{T}_{\mathrm{g} \text { PLA }}\left({ }^{\circ} \mathrm{C}\right)$ & $\mathrm{T}_{\mathrm{m} \text { PLA }}\left({ }^{\circ} \mathrm{C}\right)$ & $\mathrm{T}_{\mathrm{m} \text { PHBV }}\left({ }^{\circ} \mathrm{C}\right)$ & $\Delta \mathrm{H}_{\mathrm{m}}(\mathrm{J} / \mathrm{g})$ & $\mathrm{X}_{\mathrm{C} \text { PLA }}(\%)$ & $\mathrm{X}_{\mathrm{c} \text { PHBV }}(\%)$ & $\mathrm{T}_{\mathrm{c}}\left({ }^{\circ} \mathrm{C}\right)$ \\
\hline $1^{\text {st }}$ heating scan & & & & & & & Cooling scan \\
\hline T-100:0:0 & $57.2 \pm 0.7^{\mathrm{a}}$ & n.d. & n.d. & n.d. & n.d. & n.d. & n.d. \\
\hline T-100:0:15 & $32.6 \pm 1.4^{\mathrm{d}}$ & n.d. & n.d. & n.d. & n.d. & n.d. & n.d. \\
\hline $\mathrm{T}-0: 100: 0$ & - & - & $170.6 \pm 0.4^{b}$ & $92.0 \pm 1.9^{\mathrm{a}}$ & - & $69.7 \pm 1.4^{\mathrm{a}}$ & $129.6 \pm 1.2^{\mathrm{a}}$ \\
\hline $\mathrm{T}-0: 100: 15$ & - & - & $166.7 \pm 0.5^{d}$ & $68.7 \pm 0.4^{\mathrm{b}}$ & - & $52.0 \pm 0.3^{b}$ & $124.2 \pm 0.1^{\mathrm{b}}$ \\
\hline $\mathrm{T}-65: 35: 0$ & $53.3 \pm 0.4^{\mathrm{b}}$ & $164.9 \pm 0.2^{\mathrm{a}}$ & $172.0 \pm 0.1^{\mathrm{a}}$ & $22.0 \pm 0.9^{c}$ & $13.3 \pm 0.2^{\mathrm{a}}$ & $2.6 \pm 0.1^{\mathrm{e}}$ & $120.9 \pm 0.4^{\mathrm{c}}$ \\
\hline $\mathrm{T}-65: 35: 15$ & $24.5 \pm 1.3^{\mathrm{e}}$ & n.d. & $160.5 \pm 0.1^{\mathrm{f}}$ & $23.3 \pm 0.3^{c}$ & n.d. & $6.2 \pm 0.1^{c}$ & $109.4 \pm 0.3^{f}$ \\
\hline $\mathrm{T}-75: 25: 0$ & $50.8 \pm 0.1^{c}$ & $163.0 \pm 0.1^{b}$ & $170.8 \pm 0.2^{\mathrm{b}}$ & $10.9 \pm 0.8^{\mathrm{e}}$ & $10.6 \pm 0.3^{b}$ & $2.2 \pm 0.1^{\mathrm{e}}$ & $119.9 \pm 0.2^{\mathrm{d}}$ \\
\hline $\mathrm{T}-75: 25: 15$ & $33.9 \pm 1.3^{\mathrm{d}}$ & n.d. & $163.7 \pm 0.2^{\mathrm{e}}$ & $23.3 \pm 0.5^{c}$ & n.d. & $4.4 \pm 0.1^{\mathrm{d}}$ & $121.0 \pm 0.1^{\mathrm{c}}$ \\
\hline$C-75: 25: 15$ & $33.7 \pm 0.4^{\mathrm{d}}$ & $150.6 \pm 0.3^{c}$ & $168.2 \pm 0.3^{c}$ & $14.0 \pm 0.3^{\mathrm{d}}$ & $0.8 \pm 0.1^{\mathrm{d}}$ & $2.5 \pm 0.1^{\mathrm{e}}$ & $116.1 \pm 0.1^{\mathrm{e}}$ \\
\hline C-75:25:15-CA & $24.2 \pm 0.8^{\mathrm{e}}$ & $129.4 \pm 0.5^{\mathrm{d}}$ & $149.3 \pm 0.1^{\mathrm{g}}$ & $11.2 \pm 0.4^{\mathrm{e}}$ & $1.4 \pm 0.1^{c}$ & $1.2 \pm 0.1^{\mathrm{f}}$ & $95.6 \pm 0.1^{\mathrm{g}}$ \\
\hline Formulation & $\mathrm{T}_{\mathrm{gPLA}}\left({ }^{\circ} \mathrm{C}\right)$ & $\mathrm{T}_{\mathrm{m} \text { PLA }}\left({ }^{\circ} \mathrm{C}\right)$ & $\mathrm{T}_{\mathrm{m} \operatorname{PHBV}}\left({ }^{\circ} \mathrm{C}\right)$ & $\Delta \mathrm{H}_{\mathrm{m}}(\mathrm{J} / \mathrm{g})$ & $\mathrm{X}_{\mathrm{C} \text { PLA }}(\%)$ & $\mathrm{X}_{\mathrm{C} \text { PHBV }}(\%)$ & \\
\hline \multicolumn{8}{|l|}{$2^{\text {nd }}$ heating scan } \\
\hline $\mathrm{T}-100: 0: 0$ & $57.4 \pm 0.6^{\mathrm{a}}$ & n.d. & n.d. & n.d. & n.d. & - & \\
\hline $\mathrm{T}-100: 0: 15$ & $30.5 \pm 0.8^{\mathrm{e}}$ & n.d. & n.d. & n.d. & n.d. & - & \\
\hline $\mathrm{T}-0: 100: 0$ & - & - & $171.0 \pm 0.3^{\mathrm{a}}$ & $130.4 \pm 1.7^{\mathrm{a}}$ & - & $98.8 \pm 1.3^{\mathrm{a}}$ & \\
\hline $\mathrm{T}-0: 100: 15$ & - & - & $167.9 \pm 0.5^{b}$ & $73.4 \pm 1.2^{\mathrm{b}}$ & - & $55.6 \pm 0.9^{b}$ & \\
\hline $\mathrm{T}-65: 35: 0$ & $55.0 \pm 0.1^{\mathrm{b}}$ & n.d. & $167.3 \pm 0.4^{b}$ & $38.4 \pm 0.4^{c}$ & n.d. & $10.2 \pm 0.1^{\mathrm{c}}$ & \\
\hline T-65:35:15 & $22.7 \pm 0.3^{g}$ & $147.9 \pm 0.2^{\mathrm{a}}$ & $162.6 \pm 0.2^{\mathrm{e}}$ & $20.7 \pm 0.4^{\mathrm{e}}$ & $4.8 \pm 0.2^{b}$ & $3.6 \pm 0.2^{\mathrm{e}}$ & \\
\hline $\mathrm{T}-75: 25: 0$ & $56.5 \pm 0.1^{\mathrm{a}}$ & n.d. & $165.5 \pm 0.1^{c}$ & $32.6 \pm 0.2^{\mathrm{d}}$ & n.d. & $6.2 \pm 0.1^{\mathrm{d}}$ & \\
\hline $\mathrm{T}-75: 25: 15$ & $32.6 \pm 0.2^{\mathrm{d}}$ & $147.3 \pm 0.1^{b}$ & $160.3 \pm 0.2^{\mathrm{f}}$ & $18.2 \pm 0.3^{f}$ & $4.9 \pm 0.1^{\mathrm{a}}$ & $2.3 \pm 0.1^{\mathrm{g}}$ & \\
\hline$C-75: 25: 15$ & $37.8 \pm 0.1^{\mathrm{c}}$ & n.d. & $164.6 \pm 0.1^{d}$ & $14.1 \pm 0.1^{\mathrm{g}}$ & n.d. & $2.7 \pm 0.1^{\mathrm{f}}$ & \\
\hline C-75:25:15-CA & $26.2 \pm 0.3^{f}$ & n.d. & $148.7 \pm 0.2^{g}$ & $9.1 \pm 0.1^{\mathrm{h}}$ & n.d. & $1.0 \pm 0.1^{\mathrm{h}}$ & \\
\hline
\end{tabular}

$\mathrm{X}_{\mathrm{C} \text { PLA }}=\left(\Delta \mathrm{H}_{\mathrm{m} \text { PLA }}-\Delta \mathrm{H}_{\mathrm{C} \text { PLA }}\right) / \Delta \mathrm{H}_{0}$ PLA; with $\Delta \mathrm{H}_{0}$ PLA $=96 \mathrm{~J} / \mathrm{g}$ PLA (Kalish, Aou, Yang, \& Hsu, 2011).

$\mathrm{X}_{\mathrm{c}}$ PHBV $=\Delta \mathrm{H}_{\mathrm{m} \text { PHBv }} / \Delta \mathrm{H}_{0}$ PHBV; with $\Delta \mathrm{H}_{0}$ PHBV $=132 \mathrm{~J} / \mathrm{g}$ PHB by assuming that only PHB crystals are formed in PHBV (Miguel, Egiburu, \& Iruin, 2001). nd.: Non-detected.

$\mathrm{a}-\mathrm{h}$ : Different superscripts within the same column indicate significant differences among formulations $(\mathrm{p}<0.05)$. 
(Fig. 1), which indicates that PLA crystallized to some extent during the casting process, thus giving rise to two different crystalline domains. In this sense, it is remarkable that the crystallized PLA in cast blend films exhibited a lower melting temperature, which suggests greater polymer miscibility when the chains interact in the casting solution. This was also supported by the lower degree of crystallinity of both polymers ( $\mathrm{X}_{\mathrm{c}}$ values) when blend films were obtained by casting. As expected, CA addition in C-75:25:15 films had a significant plasticizing effect, since a clear reduction in the PLA $T_{g}$ was observed. The plasticizing effect of carvacrol and other essential oil compounds on PLA matrices was also reported by Armentano et al. (2015a) for PLA:PHBV blends with carvacrol, Arrieta, López, Hernández, and Rayón (2014c) for limonene or by Muller et al. (2017a) for cinnamaldehyde.

Supercooling effects (difference between $T_{c}$ and $T_{m}$ ) were noticed in every case. All the polyester blend formulations exhibited lower $T_{C}$ than the neat PHBV formulation and supercooling was about $40^{\circ} \mathrm{C}$ for the neat $\mathrm{PHBV}$ and $50^{\circ} \mathrm{C}$ for all the polyester blends. This is coherent with the blending effect which delays and inhibits the crystallization process.

Thermal parameters were also obtained from the second heating scan when the thermal history of the polymers was deleted (Table 2). No PLA crystallization was noticed during the second heating scan for the T-65:35:0 and T-75:25:0 films, unlike that observed during the first heating step, and only plasticized blends obtained by thermo-compression (T-65:35:15 and T-75:25:15) showed multiple-melting peaks. This is coherent with the influence of thermal history on the polymer crystallization and reflects that, under the thermal conditions of DSC analysis, PLA only crystallized when it was plasticized with PEG according to the enhancement of molecular mobility enabling the chain rearrangement in crystalline domains under the more extreme cooling rate $\left(50^{\circ} \mathrm{C} / \mathrm{min}\right)$ applied in DSC analysis.

Table 3 shows the initial degradation temperature $\left(\mathrm{T}_{\text {onset }}\right)$ and the temperature at the maximum degradation rate $\left(\mathrm{T}_{\text {peak }}\right)$ for the different degradation steps of the polyester monolayers, either thermo-processed or cast. PLA with $\mathrm{T}_{\text {peak PLA }}$ of $329 \pm 2{ }^{\circ} \mathrm{C}$ was more thermostable than PHBV with $\mathrm{T}_{\text {peak PHBV }} 233.2 \pm 0.1^{\circ} \mathrm{C}$, as reported by Ferreira et al. (2002) and Zhao, Cui, Sun, Turng, and Peng (2013). The plasticizer induced a significant decrease in the PLA's thermal stability, whereas no significant differences were observed in the PHBV-15PEG formulation with respect to the non-plasticized PHBV film. However, as reported by Requena, Jiménez, Vargas, and Chiralt (2016b), PHBV showed a second degradation step at higher temperatures associated with the PEG degradation, which overlapped to a greater extent with the main peak in the plasticized PLA films (Fig. 2). This peak was not present in 75:25 PLA-PHBV blends,

\section{Table 3}

Initial degradation temperature $\left(T_{\text {onset }}\right)$, maximum rate temperature $\left(T_{\text {peak }}\right)$ for the main degradation steps of the polyester monolayers obtained by thermocompression ( $\mathrm{T}$ ) and casting (C) at different PLA:PHBV:PEG ratios. Mean values \pm standard deviation.

\begin{tabular}{llll}
\hline Formulation & $\mathrm{T}_{\text {onset }}$ & $\mathrm{T}_{\text {peak PHBV }}$ & $\mathrm{T}_{\text {peak PLA }}$ \\
\hline T-100:0:0 & $309 \pm 2^{\mathrm{a}}$ & - & $329 \pm 2^{\mathrm{a}}$ \\
T-100:0:15 & $281 \pm 4^{\mathrm{b}}$ & - & $314 \pm 3^{\mathrm{c}}$ \\
T-0:100:0 & $233 \pm 1^{\mathrm{d}}$ & $243 \pm 1^{\mathrm{c}}$ & - \\
T-0:100:15 & $229 \pm 3^{\mathrm{de}}$ & $241 \pm 3^{\mathrm{c}}$ & - \\
T-65:35:0 & $226 \pm 7^{\mathrm{def}}$ & $241 \pm 1^{\mathrm{c}}$ & $300 \pm 1^{\mathrm{e}}$ \\
T-65:35:15 & $216 \pm 3^{\mathrm{f}}$ & $239 \pm 4^{\mathrm{c}}$ & $286 \pm 8^{\mathrm{f}}$ \\
T-75:25:0 & $225 \pm 1^{\text {def }}$ & $240 \pm 2^{\mathrm{c}}$ & $306 \pm 3^{\mathrm{d}}$ \\
T-75:25:15 & $219 \pm 7^{\text {ef }}$ & $235 \pm 5^{\mathrm{c}}$ & $297 \pm 1^{\mathrm{e}}$ \\
C-75:25:15 & $236 \pm 1^{\mathrm{c}}$ & $254 \pm 1^{\mathrm{b}}$ & $317 \pm 2^{\mathrm{bc}}$ \\
C-75:25:15-CA & $92 \pm 1^{\mathrm{g}}$ & $257 \pm 1^{\mathrm{a}}$ & $320 \pm 1^{\mathrm{b}}$ \\
\hline
\end{tabular}

a-g: Different superscripts within the same column indicate significant differences among formulations $(\mathrm{p}<0.05)$. which suggests a better integration of the plasticizer in this matrix. The PLA-PHBV blend formulations exhibited two different degradation steps corresponding to both polyesters, according to the lack of polymer miscibility. However, the degradation temperatures in the blends were lower than those corresponding to the pure polymer, which suggests their partial miscibility. The addition of both $25 \%$ and $35 \%$ of PHBV provoked a remarkable decrease in the PLA thermal stability, as reported by Ferreira et al. (2002) and Modi, Koelling, \& Vodovotz (2012) for PLA-PHBV mixtures. This effect was more marked when blends contained PEG. In contrast, the changes in the temperature of thermal degradation were not significant in the PHBV phase.

The TGA analysis also demonstrated that the film formation process significantly affected the thermal stability of polymers. Casting led to polyester blend monolayers with significantly greater thermal stability than the corresponding thermo-processed formulation, probably due to some thermal degradation that previously took place during thermoprocessing. Cast films containing CA exhibited a progressive weight loss up to about $250^{\circ} \mathrm{C}$ $\left(\mathrm{T}_{\text {peak }}=175^{\circ} \mathrm{C}\right)$, associated with the compound volatilization; however, no remarkable change in the peak temperatures of polymers was observed, while the separate peak associated with PEG was also present in these films, as opposed to that observed for the same formulation obtained by casting. Again, the influence of the processing method on the interactions established between the polymer chains was reflected.

DSC and TGA reveal polymer-phase separation in the polyester blend films, with a partial miscibility, containing different domains richer in PLA or in PHBV. A lower degree of PHBV crystallinity was observed in the blends ( $\mathrm{X}_{\mathrm{c}}$ PHBV $)$, whereas PLA crystallization was observed, despite the amorphous nature of the polymer used, induced by PHBV. In the same sense, Mofokeng and Luyt (2015) reported PLA-PHBV (70:30) blend micrographs where PHBV appears dispersed in spherical domains in a continuous PLA phase. In contrast, Modi et al. (2012) reported a partial compatibility between both polymers in PLA-PHBV blends, associated with the decrease in the PLA $T_{g}$, and no phase separation was observed by SEM.

\subsection{Characterization of the polyester-starch bilayer films}

\subsubsection{CA retention in bilayer films}

Gravimetric determinations, for the bilayer films with $C A$ sprayed at the interface of thermo-processed monolayers (TP-CA-S) before and after the second thermo-compression step, showed a mass loss of $33 \pm 3 \%$ due to the partial polymer (mainly starch) radial flow during compression, which was enhanced by the plasticizing effect of the CA. Thus, significant losses of the active compound incorporated in the bilayer could occur during this step. Then, the radial distribution of the CA in both newly-prepared films (D0) and those stored for 6 days (D6) was analysed (Table 4). CA was heterogeneously distributed according to the film radius, the outer area $(7.0-7.5 \mathrm{~cm})$ being the richest in CA in both the newly prepared and stored films. This confirmed the radial flow of the sprayed active compound during thermo-compression and the CA resistance to the internal diffusion inside the matrix both during the compression step and the film storage. Therefore, and given that the circular crown from 7.0 to $7.5 \mathrm{~cm}$ was discarded for both physical and antimicrobial analysis, the mean CA concentration estimated in the bilayer films was $1.2 \mathrm{~g} \mathrm{CA} / 100 \mathrm{~g}$ of film with a heterogeneous distribution.

In cast films $(\mathrm{CP}(\mathrm{CA}))$, a homogenous distribution of $\mathrm{CA}$ was assumed, since loaded monolayer comes from a solution, and the extraction with methanol gave $19.8 \pm 0.3 \mathrm{~g} \mathrm{CA} / 100 \mathrm{~g}$ monolayer. Likewise, a homogenous distribution was assumed in the $\mathrm{CP}(\mathrm{CA})-\mathrm{S}$ 
A

T-100:0:0
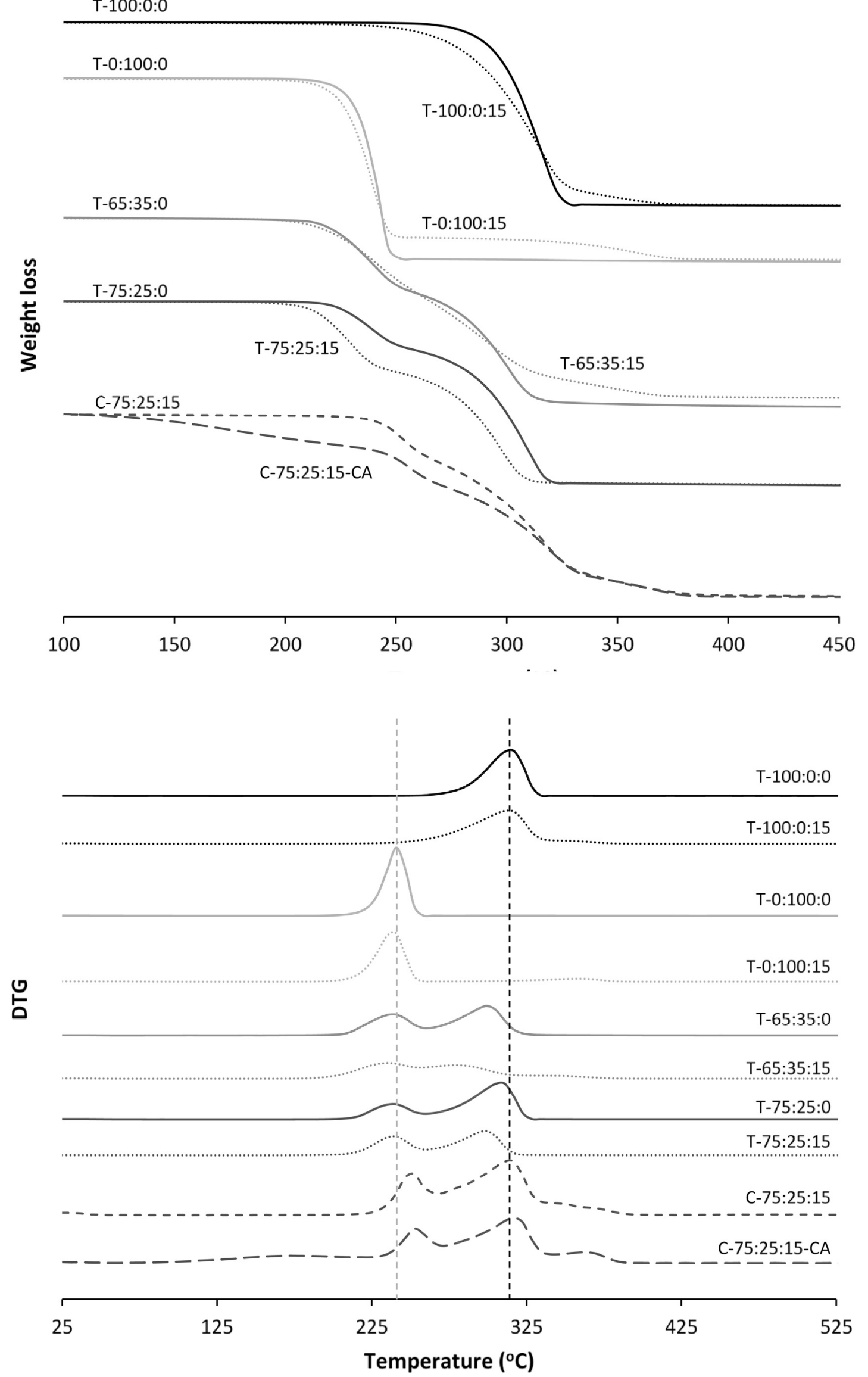

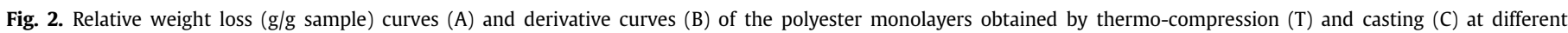
PLA:PHBV:PEG ratios. 
bilayer where methanol extraction led to $8.2 \pm 0.2 \mathrm{~g} \mathrm{CA} / 100 \mathrm{~g}$ bilayer. Both analysed CA contents were very close to the theoretical values ( $8.3 \mathrm{~g} \mathrm{CA} / \mathrm{g}$ bilayer and $19.9 \mathrm{CA} / 100 \mathrm{~g}$ monolayer), which indicates that no significant losses in CA occurred during the monolayer casting process or bilayer thermocompression.

\subsubsection{Physical properties}

Both polyester-starch bilayer structures, TP-S and CP-S, were less stiff and resistant than the respective polyester monolayer, with elongation percentages in the range of their corresponding polyester monolayer (Table 5). However, both of them were significantly stiffer and more resistant than the $\mathrm{S}$ monolayer, although much less extensible. The kind of polyester processing affected the tensile behaviour of bilayer films. Thus, cast polyester sheets led to stiffer bilayer films (CP-S and $\mathrm{CP}(\mathrm{CA})-\mathrm{S}$ ), due to their contribution to the overall stiffness of the bilayer film because of the greater resistance and stiffness of cast polyester. Nevertheless, TP-CA-S films were significantly more extensible than the rest of the bilayers, probably due to the CA diffusion in both $\mathrm{S}$ and $\mathrm{P}$ layers from the interface, thus plasticizing them and enhancing their stretchability, especially in the polymeric material near to the interface, where the break mainly occurs.

Coherently with the respective WVP of TP and CP monolayers, TP-S bilayer films exhibited lower WVP values than CP-S. Although the bilayer assemblies always had higher WVP than their corresponding polyester sheets, both CA-free bilayers, TP-S and CP-S, had reduced WVP values (95\% and $89 \%$ reduction, respectively) with respect to the $S$ monolayer. No significant differences were noticed between the WVP values of the CP-S and CP(CA)-S bilayers, whereas spraying CA at the interface significantly increased the WVP of the TP-S bilayers. This proves once again the great impact of the processing method on the functional properties of both mono and bilayer assemblies, in particular, differing interactions of CA with the polymer matrices could be deduced from the contrasting effect it had on the bilayer properties. Similar tendencies were obtained when materials with different water vapour barrier capacity were combined in multilayer structures, such as gluten-PE (Irissin-Mangata, Boutevin, \& Bauduin, 1999), gelatine-PLA (Martucci \& Ruseckaite, 2010) or starch-PCL (Ortega-Toro, Morey, Talens, \& Chiralt, 2015). As concerns the barrier properties, the controlling layer of the mass transport is always the one which offers the highest barrier capacity. The polyester-starch bilayers obtained by the different methods were fully effective at controlling the water vapour permeation, due to the barrier capacity of the polyester sheets, whereas a good oxygen barrier capacity was expected owing to the barrier effect of the $\mathrm{S}$ sheet (oxygen permeability: $0.123 \cdot 10^{-12} \mathrm{~cm}^{3} \mathrm{~m}^{-1} \mathrm{~s}^{-1} \mathrm{~Pa}^{-1}$ (Muller et al., 2017a)).

Although no significant differences were observed in the monolayer thickness regardless of the processing method, TP-S bilayers were significantly thinner than CP-S, due to the radial flow of both monolayers during the thermo-compression step. This indicates the greater flowability of TP as compared to CP; this was significantly enhanced when CA was sprayed at the interface (TPCA-S), since all the active compound and polymer monolayers flowed radially because of the pressure action, as previously commented on.

\subsubsection{Thermal properties}

The TGA analysis of the starch-polyester bilayers revealed thermal behaviour similar to that of the S monolayer (Fig. 3), thus showing an initial mass loss associated with the water linked to the starch and the subsequent degradation of the polymeric material. The higher mass fraction of the S monolayer in the bilayer (61.5\%) and the greater proportion of PLA in the polyester monolayer (63.75\%) make the PHBV a minor compound (6.54\% of the bilayer) and its thermal degradation was barely appreciable. Both PLA and starch exhibited similar degradation temperatures, which overlap in the TGA curve. However, the CP-S bilayer films exhibited a shoulder in the DTG curves at higher temperatures attributable to the end of PLA degradation, due to the greater thermal stability of PLA in cast monolayers, as previously commented on. As regards the CA mass loss in starch-polyester systems containing CA (TP-CA$\mathrm{S}$ and $\mathrm{CP}(\mathrm{CA})-\mathrm{S})$, significant differences could be observed. Despite the fact that the same initial amount of CA was incorporated into the bilayers, $\mathrm{CP}(\mathrm{CA})-\mathrm{S}$ films exhibited a higher mass loss associated with the CA volatilization than the TP-CA-S, in agreement with the greater retention of the compound during bilayer processing, as previously commented on. The $\mathrm{T}_{\text {peak }}$ for CA volatilization in bilayers was $125^{\circ} \mathrm{C}$ compared to $175^{\circ} \mathrm{C}$ found in the CA-loaded P monolayer. This difference could be attributed to the partial diffusion of CA into the starch sheet, which could release CA at lower temperatures, in line with its residual water content (steam drag effect), which was lost up to about $100^{\circ} \mathrm{C}$.

\subsection{Release kinetics of CA and antimicrobial activity}

The antimicrobial properties of the different monolayer and bilayer films were analysed against Gram + (L. innocua) and Grambacteria (E.coli). No significant microbial growth reductions $(<1 \log )$ were observed when CA was sprayed at the interface between thermo-processed polyester and starch sheets, in contrast with that reported in previous studies using active PHBV bilayers with CA sprayed at the interface (Requena et al., 2016a). Whereas PHBV bilayer films permitted an appropriate CA retention in the films and, therefore, significant antibacterial activity, the TP-CA-S bilayers did not result in an effective assembly from the antimicrobial point of view, due to the insufficient CA retention, associated with the radial flow of the material during thermocompression. The amount of CA released from the film into the culture medium after 6 contact days was estimated from the difference between the CA content in the films after this period and the initial content, both determined by methanol extraction. Thus, the amount of active compound released from the film into the culture medium $\left(9 \cdot 10^{-5} \mathrm{~g} / \mathrm{ml}\right)$ was significantly lower than the MIC of this active compound for L. innocua $\left(3.7 \cdot 10^{-4} \mathrm{~g} / \mathrm{ml}\right)$ and $E$. coli $\left(3.1 \cdot 10^{-4} \mathrm{~g} / \mathrm{ml}\right)$ (Burt, 2004; Ye et al., 2013), which explains the lack of antimicrobial activity of this bilayer assembly.

Fig. 4 shows microbial counts of E. coli and L. innocua (CFU/g) for both active films (cast polyester monolayer containing carvacrol: $\mathrm{CP}(\mathrm{CA})$; bilayer film with starch: $\mathrm{CP}(\mathrm{CA})-\mathrm{S})$ and the corresponding control formulations ( $\mathrm{CP}$ and $\mathrm{S}$ ) after incubating for 6 days. In the case of the bilayers, two different tests were carried out: the $\mathrm{CP}$ or the $S$ layers in contact with the inoculated agar plate (CP(CA)-S and $\mathrm{S}-\mathrm{CP}(\mathrm{CA})$, respectively). Unlike the results obtained for TP-CA-S, when CA was incorporated into the polyester casting solution, the resulting bilayer structure exhibited significant antimicrobial activity, in line with the greater CA retention. This fact reveals the importance of the method used to develop active films. CP control samples had no significant effects on the microbial growth of either bacteria, whereas S control samples slightly increased both microbial counts, since starch is a potential growth substrate for bacteria. Therefore, the antimicrobial activity observed for both bilayers containing CA must be attributed to its antimicrobial activity and to an adequate release of the active compound into the culture medium. Both $\mathrm{CP}(\mathrm{CA})$ and $\mathrm{CP}(\mathrm{CA})-\mathrm{S}$ films significantly reduced the microbial growth of both bacteria ( 9 and $5 \log \mathrm{CFU}$, respectively), with $E$. coli being more sensitive, as reported by Requena et al. (2016a). Likewise, microbial growth reductions of 5 and $6 \log$ CFU were reported against L. monocytogenes and Salmonella typhimurium, respectively, in chicken samples with cast PLA 
Table 4

Carvacrol (CA) distribution in newly-prepared TP-CA-S bilayer films (D0) and after 6 days of storage at $53 \% \mathrm{HR}$ (D7). Mean values \pm standard deviation.

\begin{tabular}{lll}
\hline Sample radius $(\mathrm{cm})$ & D0 $(\mathrm{g} \mathrm{CA} / 100 \mathrm{~g}$ film $)$ & D6 $(\mathrm{g} \mathrm{CA} / 100 \mathrm{~g} \mathrm{film})$ \\
\hline $0-3.0 \mathrm{~cm}$ & $0.9 \pm 0.3^{\mathrm{a} 1}$ & $0.7 \pm 0.2^{\mathrm{a} 1}$ \\
$3.0-5.0 \mathrm{~cm}$ & $0.9 \pm 0.1^{\mathrm{a} 1}$ & $1.4 \pm 0.5^{\mathrm{a} 1}$ \\
$5.0-7.0 \mathrm{~cm}$ & $1.5 \pm 0.3^{\mathrm{b} 1}$ & $1.2 \pm 0.2^{\mathrm{a} 1}$ \\
$7.0-7.5 \mathrm{~cm}$ & $3.4 \pm 0.4^{\mathrm{c} 1}$ & $4.2 \pm 1.4^{\mathrm{b} 1}$ \\
\hline
\end{tabular}

a-c: Different superscripts within the same column indicate significant differences among samples $(\mathrm{p}<0.05)$.

1-2: Different superscripts within the same line indicate significant differences for the same sample at different storage time $(\mathrm{p}<0.05)$.

films containing 25\% of cinnamon (Ahmed, Mulla, \& Arfat, 2016). The bilayers were always less effective than the CA-loaded monolayers (despite having the same CA content per surface unit of film), whose application leads to a total growth inhibition of $E$. coli. The fact that the bilayers are less effective could be attributed to a more limited CA release due to the internal diffusion of the compound into a thicker structure; this represents a longer pathway for molecular diffusion and, therefore, more time needed for a determined amount to be released.

Although no significantly different antimicrobial action was observed between the CA-loaded bilayer for $S$ contact ( $\mathrm{S}-\mathrm{CP}(\mathrm{CA})$ ) or $\mathrm{CP}$ contact $(\mathrm{CP}(\mathrm{CA})-\mathrm{S}$ ) with the culture medium against $E$. coli, more marked antilisterial effects were observed when the $S$ layer was in contact with the culture media. This could be attributed to the greater water affinity of the S layer, which promoted the swelling of the polymer matrix in contact with the culture medium, which, in turn, accelerated the release of the active compound. The obtained results also proved that the active compound diffused into both $\mathrm{CP}$ and $S$ sheets, giving rise to antimicrobial activity through both sides of the bilayers. The active amount released and its release rate through each layer will influence how effective each side of the bilayer is at controlling the microbial growth inhibition. Hence, the incorporation of CA dissolved in the polyester casting solution and the formation of an active layer by casting was effective at developing antimicrobial polyester-starch bilayer films, with improved tensile and barrier properties as compared to the neat starch films.

Based on the above-mentioned results from the CA retention and the resulting antimicrobial activity, CA release kinetic studies were only carried out for the cast polyester monolayer (CP(CA)) and the corresponding bilayer with starch $(\mathrm{CP}(\mathrm{CA})-\mathrm{S})$. This was studied in four food simulants with different polarities. Aqueous (A: 10\% ethanol (v/v) and B: $3 \%$ acetic acid (w/v)) and less polar simulants (D1: $50 \%$ ethanol (v/v) and D2: isooctane) were considered. The CA released into the simulants at different contact times was determined, thus obtaining Fig. 5, which shows the mean values of the amount of released CA referred to the initial amount of CA in the films (points). These data were fitted to Peleg's model (lines) in order to determine the maximum amount of CA delivered at equilibrium $\left(\mathrm{M}_{\infty}\right)$, referred per mass unit of the initial film, in each simulant (Table 6 ). The values of the $1 / \mathrm{k}_{1}$ parameter, related to the initial release rate of the compound, are also summarized in Table 6. A good fit of the model was achieved in every case $\left(R_{2}>0.97\right)$. Both Peleg's parameters were significantly affected by the food simulant's polarity and the fastest CA release was achieved in 50\% ethanol (D1 simulant) for both mono and bilayer films, as previously reported by Requena, Vargas, and Chiralt (2017b) for CAloaded PHBV bilayers. In contrast, the highest CA amount released at equilibrium $\left(\mathrm{M}_{\infty}\right)$ from the polyester monolayer occurred in the less polar simulants (isooctane or $50 \%$ ethanol), whereas for the bilayer this occurred in the D1 (50\% ethanol) solvent, while the $M_{\infty}$ value in isooctane was much lower than in $50 \%$ ethanol. This could be related with the role of the starch sheet in the bilayer's CA delivery, with the greater affinity with the more polar simulant, which contributed to the swelling of the polymer and faster compound diffusion. In both cases, the amount of CA released at equilibrium was significantly lower in the polar simulants (A and B). This agrees with what was previously reported by other authors for the release of essential oil compounds form polymer matrices, which was enhanced as the ethanol ratio in the solvent increased, due to the greater solubility of the active compound in the solvent (Narayanan \& Ramana, 2013; SánchezGonzález, Cháfer, González-Martínez, Chiralt, \& Desobry, 2011; Tawakkal, Cran, \& Bigger, 2016). Thus, the maximum expected delivery of CA from the $\mathrm{CP}(\mathrm{CA})$ films would occur in non-polar food, those containing free fats on the surface, whereas the maximum expected released from $\mathrm{CP}(\mathrm{CA})-\mathrm{S}$ bilayer films would be expected in foodstuffs of intermediate polarity, such as alcoholic beverages or oil-in-water emulsions (sauces, dressings or high fat dairy products). Conversely, a lower CA delivery would be expected when applied to aqueous food packaging.

Two different steps can be noticed as regards the CA release from monolayer films into $3 \%$ acetic acid, probably due to the partial polyester hydrolysis induced by the acid medium during the first contact period which could open the film's microstructure, favouring the subsequent compound release (Fig. 5). This pattern was not observed for the CA release from the bilayer film in the same solvent, probably due to the greater contribution of the starch sheet to the CA release in this aqueous solvent. However, this twostep behaviour can also be distinguished for the CA release from bilayer films in $50 \%$ ethanol, which suggests a different release rate of CA from the different polymer sheets in this solvent. This effect would be expected in any case since each polymer exhibited a different chemical affinity with CA and the solvent, establishing a different partition coefficient in each case. However, the experimental points did not permit the decoupling of the CA release from each sheet in every case and the overall behaviour was analysed.

Table 6 also shows the maximum release ratio of $\mathrm{CA}(\mathrm{M} \infty / \mathrm{M} 0)$ from the monolayer and the bilayer structures, defined as the mass of CA released at equilibrium in the simulant related to the initial amount in the film. Thus, practically the entire amount of CA was delivered in isooctane for the monolayer $\mathrm{CP}(\mathrm{CA})$ film $(85.9 \pm 0.5 \%)$

Table 5

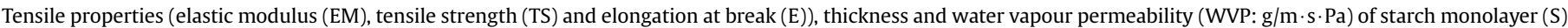

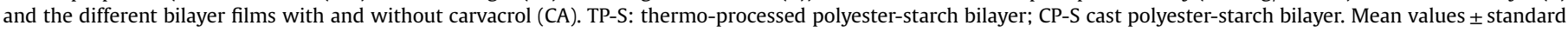
deviation.

\begin{tabular}{|c|c|c|c|c|c|}
\hline Formulation & $\mathrm{EM}(\mathrm{MPa})$ & TS (MPa) & $E(\%)$ & Thickness $(\mu \mathrm{m})$ & WVP $\left(\times 10^{-12}\right)$ \\
\hline TP-S & $290 \pm 40^{c}$ & $5.0 \pm 0.7^{b}$ & $3 \pm 2^{c}$ & $174 \pm 10^{c}$ & $14 \pm 2^{c}$ \\
\hline TP-CA-S & $180 \pm 40^{\mathrm{d}}$ & $5.2 \pm 0.7^{b}$ & $25 \pm 4^{b}$ & $161 \pm 12^{\mathrm{cd}}$ & $57 \pm 7^{\mathrm{e}}$ \\
\hline CP-S & $760 \pm 30^{\mathrm{a}}$ & $9.2 \pm 1.3^{\mathrm{a}}$ & $1.4 \pm 0.4^{c}$ & $251 \pm 7^{\mathrm{a}}$ & $32 \pm 5^{d}$ \\
\hline $\mathrm{CP}(\mathrm{CA})-\mathrm{S}$ & $480 \pm 50^{\mathrm{b}}$ & $5.2 \pm 1.6^{\mathrm{b}}$ & $1.2 \pm 0.6^{c}$ & $216 \pm 16^{b}$ & $38 \pm 5^{d}$ \\
\hline S & $50 \pm 10^{\mathrm{e}}$ & $4.1 \pm 0.3^{b}$ & $75 \pm 7^{a}$ & $155 \pm 8^{d}$ & $283 \pm 6^{f}$ \\
\hline
\end{tabular}

a-f: Different superscripts within the same column indicate significant differences among formulations $(p<0.05)$. 
A

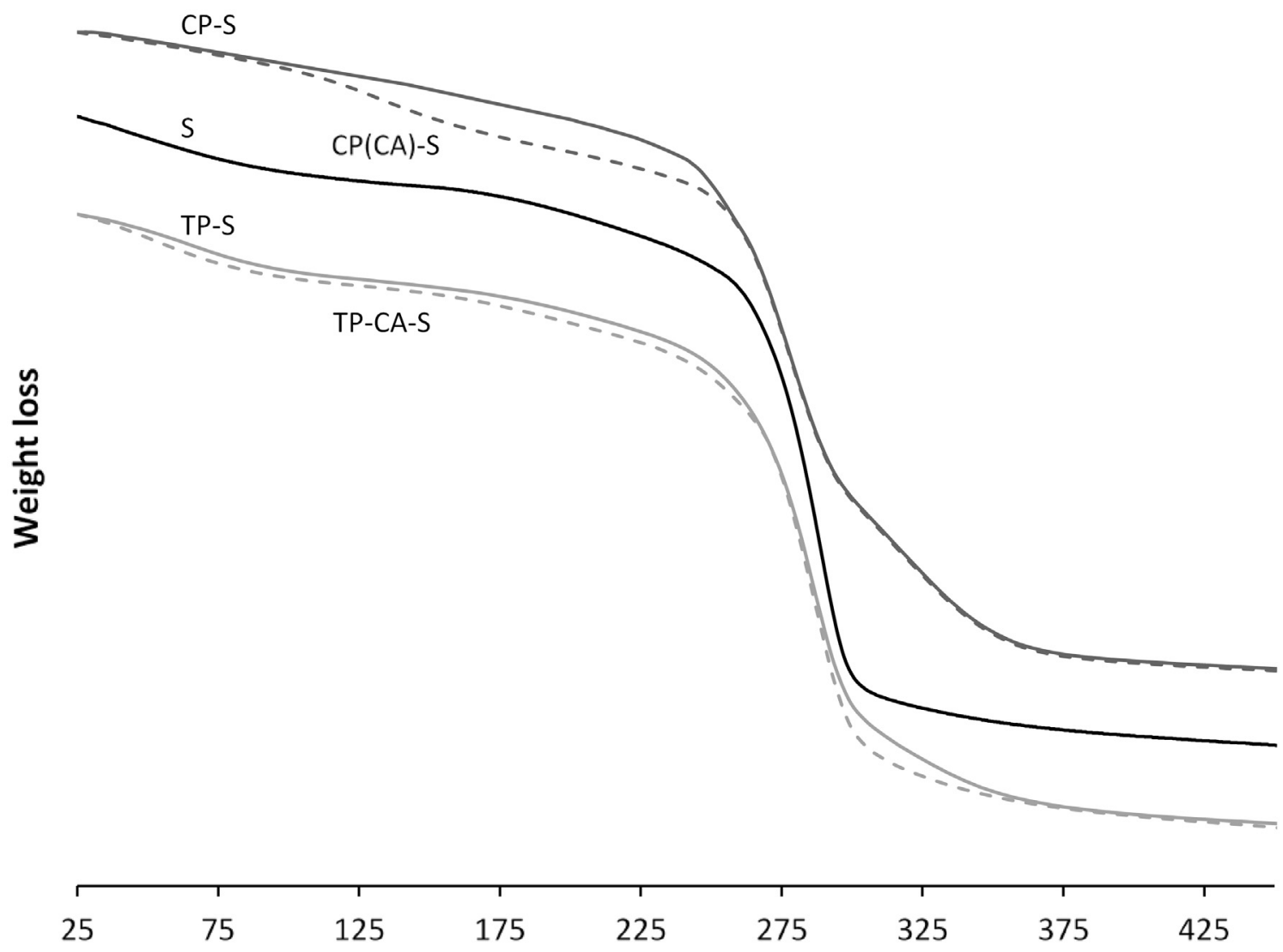

B

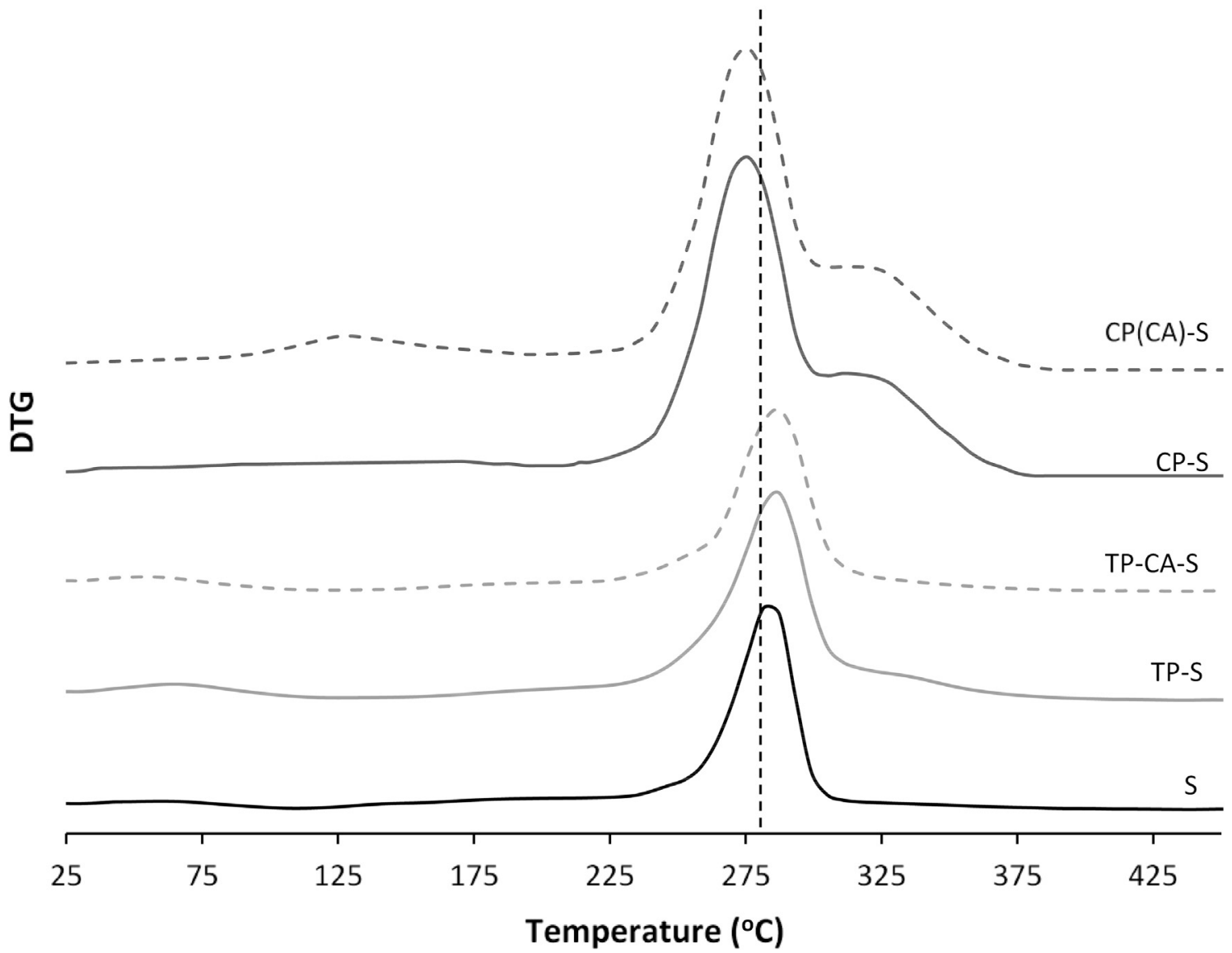

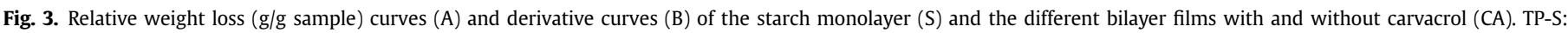
thermo-compressed polyester-starch bilayer; CP-S cast polyester-starch bilayer. 


\section{Listeria innocua}

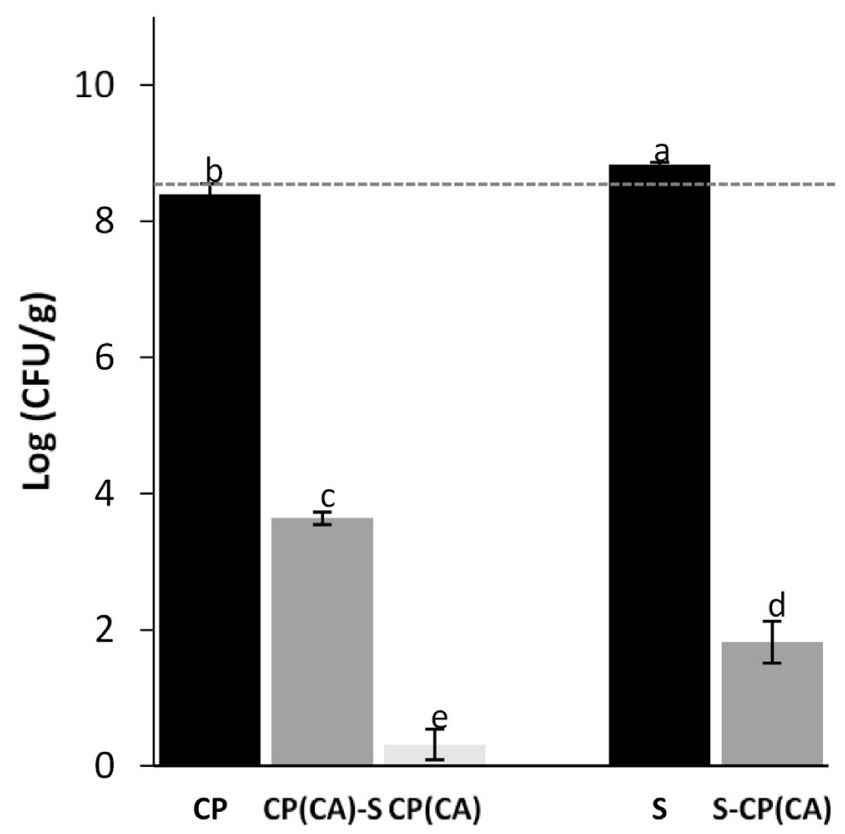

Escherichia coli

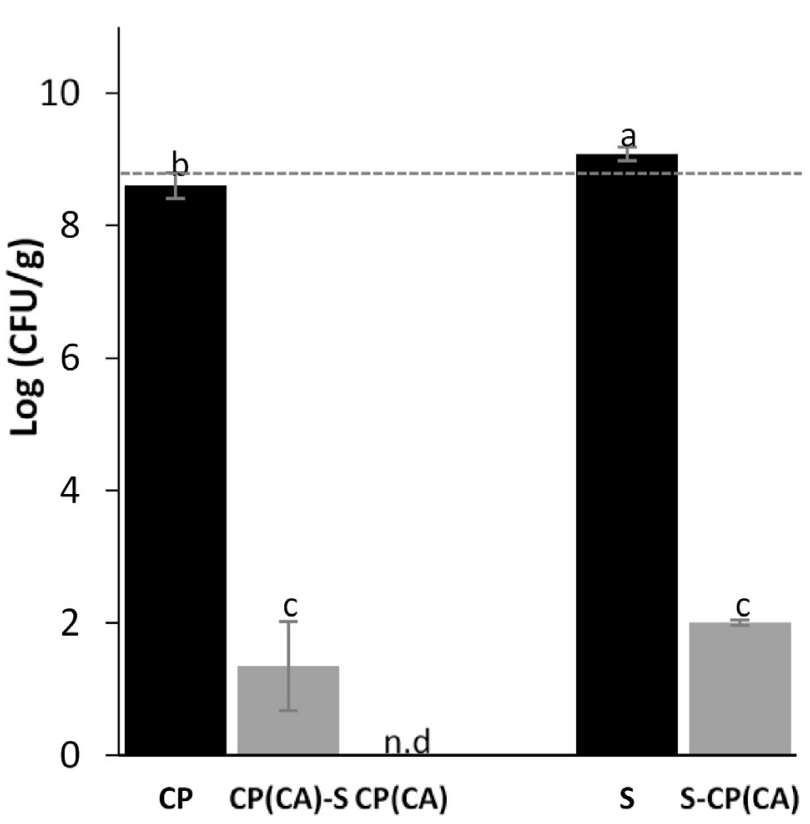

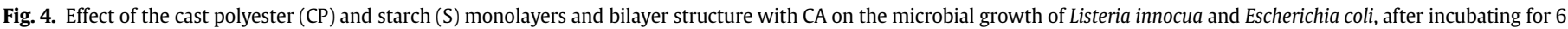

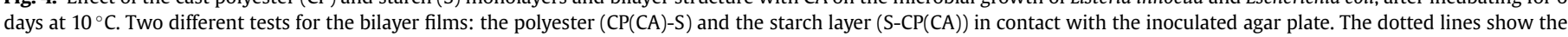

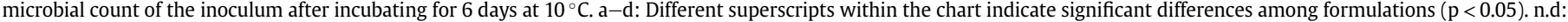
non detected.

and total delivery was achieved in 50\% ethanol for the bilayer $\mathrm{CP}(\mathrm{CA})-\mathrm{S}(112 \pm 14 \%)$. The largest quantity of CA released at equilibrium from the bilayer in the simulant of intermediate polarity coincided with the internal diffusion of CA towards the starch sheet, with weaker interactions with CA, and with less tendency to retain it against delivery into the food simulant in the second step of the release period. Nevertheless, both monolayer and bilayer films showed a maximum release ratio of about $20 \%$ in aqueous systems (A and B simulants), with no significant differences between them. All these aspects reflect the different solvent interactions with both polymer sheets which, in turn, affect the final partition coefficient of CA between the two polymer layers and the solvent. In this sense, three coupled mechanisms are involved in the release process of the active compounds from the films: the solvent diffusion into the polymer matrix, the relaxation of the macromolecular network and the diffusion of the active compound through the relaxed polymer matrix, until the thermodynamic equilibrium between film and food system is reached (Requena et al., 2017a). Different factors influence the compound release, such as the polarity and solubility of the migrant and the polymercompound affinity, which determine their interactions, and the solubility of the compound in the food system or simulant. Thus, in the case of bilayer films, both polymer matrices (starch and polyester blend layers) are expected to interact differently with both migrant and solvent and so they contribute to differing extents to the release rate and final partition of the compound. Nonetheless, a general tendency was observed in the behaviour of the CA released from bilayer films.

No coupling of the polymer relaxation and compound diffusion was reported for similar compounds in different polymer matrices, the diffusion being the controlling mechanism of the active compound release as reported by some authors in the case of limonene in chitosan films (Sánchez-González et al., 2011) or thymol in zein (Del Nobile, Conte, Incoronato, \& Panza, 2008), PLA (Tawakkal et al.,
2016) and PBS films (Petchwattana \& Naknaen, 2015). Then, the overall diffusion coefficient (D) of CA in both mono and bilayers was estimated in each simulant. Fig. 6 shows the values of $\left(\mathrm{M}_{\mathrm{t}} / \mathrm{M}_{\infty}\right) v s$. contact time (points) and Fick's model fitted to the experimental data in each simulant (lines). A good fit of the model can be observed in every case (SSE $<0.04$ ), as well as the different pattern of the curves depending on the simulant and the film. Nevertheless, the two expected steps could be observed for the CA delivery from $\mathrm{CP}(\mathrm{CA})-\mathrm{S}$ bilayer films into $10 \%$ and $50 \%$ ethanol, due to the different contribution of both layers in the release process throughout the contact time (Fig. 6), depending on the relative affinity of the matrix with the solvent and diffusing compound. This agrees with the different antibacterial activity observed for the bilayer in contact with the culture medium in its different layer, whose CA release differed depending on the polymer in contact with the culture medium.

The CA diffusion coefficient (D) values of the monolayer in the different simulants are in line with the release rates estimated from Peleg's model; the highest D values were obtained in 50\% ethanol (Table 6). Similar results have been reported by Tawakkal et al. (2016) and Petchwattana and Naknaen (2015) for thymol diffusion from PLA and PBS films, respectively. In contrast, the values of the CA diffusion were lower in the bilayers in every simulant except for $3 \%$ acetic acid, where it reached the highest value. The internal diffusion of CA in the bilayer assembly and the establishment of different interactions with both polymer sheets hid the compound's ability to diffuse towards the simulant, which is also dependent on the respective polymer relaxation with the solvent diffusion.

From the release kinetics, and assuming a bulk diffusion into the culture medium, which could be simulated by simulant $A(10 \%$ ethanol), the amount of CA released after 6 contact days $\left(M_{\infty}\right.$, since the equilibrium has already been reached at that time) from the monolayer and bilayer films could be estimated. These amounts 

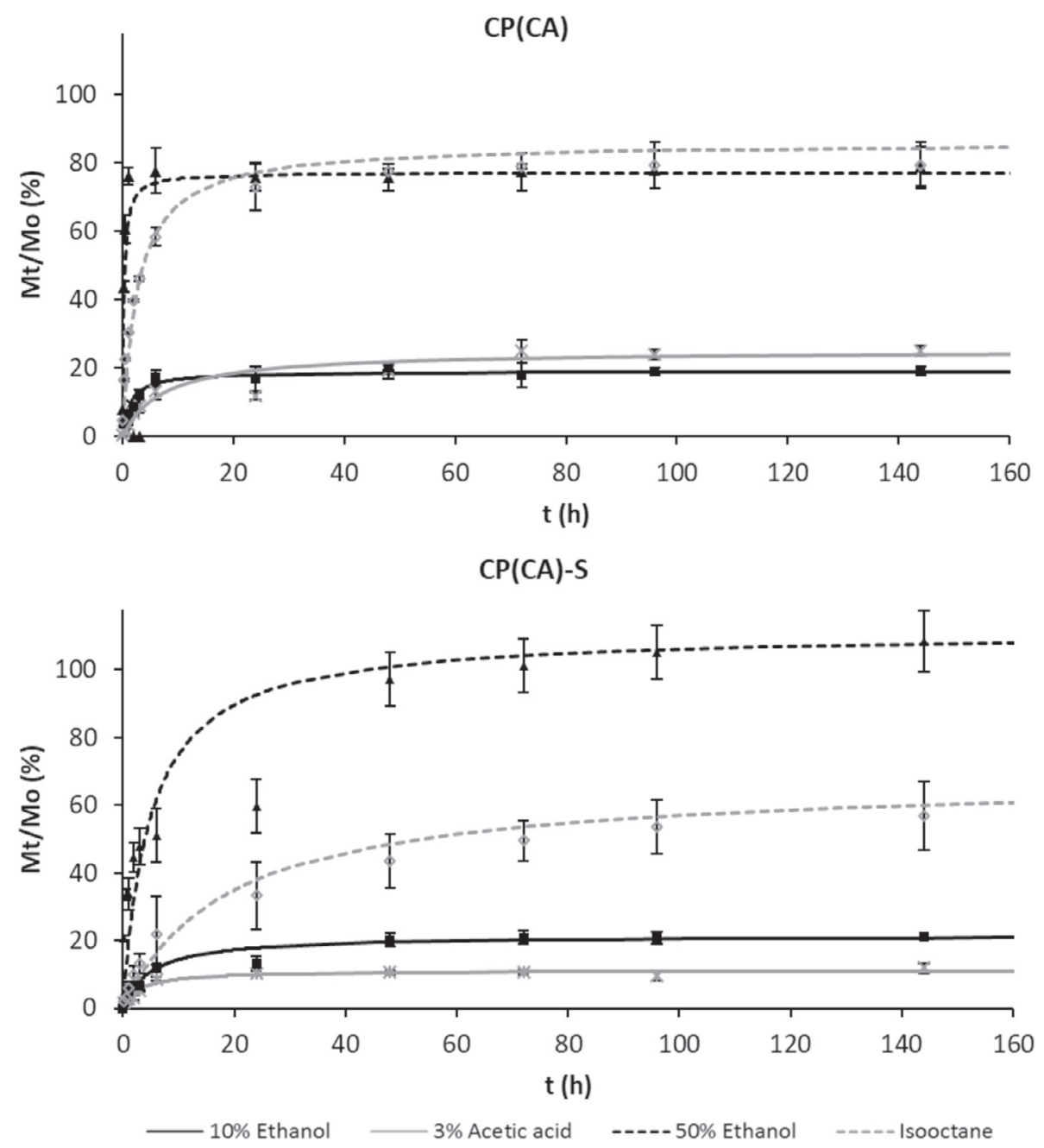

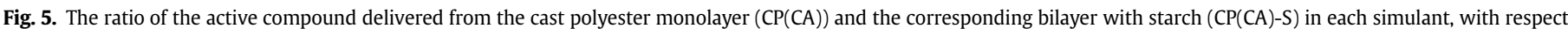

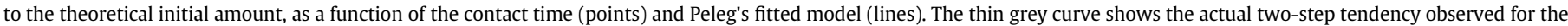
$\mathrm{CP}(\mathrm{CA})$ monolayer in $3 \%$ acetic acid and the $\mathrm{CP}(\mathrm{A})-\mathrm{S}$ bilayer in 10 or $50 \%$ ethanol.

were $1.2 \cdot 10^{-3} \mathrm{~g} / \mathrm{ml}$ and $1.3 \cdot 10^{-3} \mathrm{~g} / \mathrm{ml}$ for mono and bilayer, respectively, which are significantly higher than the MIC of this active compound against L. innocua $\left(3.7 \cdot 10^{-4} \mathrm{~g} / \mathrm{ml}\right)$ and $E$. coli $\left(3.1 \cdot 10^{-4} \mathrm{~g} / \mathrm{ml}\right.$ ) (Burt, 2004; Ye et al., 2013), coherent with the observed antibacterial effect.

\section{Conclusion}

The properties of thermoprocessed PLA-PHBV blends were affected by the polymer proportion and the presence of PEG as plasticizer. The PLA glass transition and crystallinity of both polymers changed in the different blends, indicating the presence of different domains richer in either PLA or PHBV, with limited partial miscibility, all of which is affected by the different PEG plasticization of such domains. The 75:25 PLA-PHBV formulation with PEG exhibited the best overall properties in terms of extensibility and water vapour permeability and, thus, was used to be the carrier of carvacrol by casting. This formulation was stiffer and less

Table 6

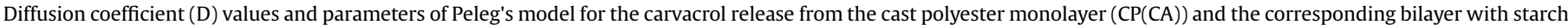

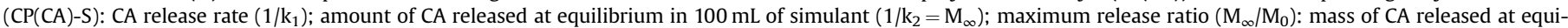
librium in the simulant related to the theoretical incorporated amount. Mean values \pm standard deviation.

\begin{tabular}{|c|c|c|c|c|c|c|}
\hline Simulant & Film & $1 / \mathrm{k}_{1}(\mu \mathrm{g} / \mathrm{s})$ & $1 / \mathrm{k}_{2}=\mathrm{M}_{\infty}\left(\mathrm{mg} \mathrm{CA} / \mathrm{cm}^{2} \mathrm{film}\right)$ & $1 / \mathrm{k}_{2}=\mathrm{M}_{\infty}(\mathrm{g} \mathrm{CA} / 100 \mathrm{~g}$ film $)$ & $\mathrm{M}_{\infty} / \mathrm{M}_{0}(\%)$ & $\mathrm{D} \cdot 10^{-14}\left(\mathrm{~m}^{2} / \mathrm{s}\right)$ \\
\hline \multirow[t]{2}{*}{ 3\% Acetic acid } & $\mathrm{CP}(\mathrm{CA})$ & $1.0 \pm 0.2^{\mathrm{de}}$ & $0.71 \pm 0.07^{\mathrm{d}}$ & $5.1 \pm 0.5^{\mathrm{d}}$ & $25 \pm 3^{d}$ & $2 \pm 1^{d}$ \\
\hline & $\mathrm{CP}(\mathrm{CA})-\mathrm{S}$ & $0.6 \pm 0.3^{\mathrm{ef}}$ & $0.32 \pm 0.05^{\mathrm{f}}$ & $1.1 \pm 0.2^{g}$ & $11 \pm 2^{\mathrm{e}}$ & $15 \pm 6^{\mathrm{b}}$ \\
\hline \multirow[t]{2}{*}{$10 \%$ Ethanol } & $\mathrm{CP}(\mathrm{CA})$ & $6.0 \pm 2.0^{\mathrm{bcd}}$ & $0.53 \pm 0.03^{\mathrm{e}}$ & $3.8 \pm 0.2^{\mathrm{e}}$ & $19 \pm 1^{d}$ & $30 \pm 10^{\mathrm{b}}$ \\
\hline & $\mathrm{CP}(\mathrm{CA})-\mathrm{S}$ & $0.6 \pm 0.1^{\mathrm{f}}$ & $0.60 \pm 0.06^{\mathrm{de}}$ & $2.2 \pm 0.2^{f}$ & $22 \pm 2^{\mathrm{d}}$ & $5 \pm 1^{\mathrm{c}}$ \\
\hline \multirow[t]{2}{*}{ 50\% Ethanol } & $\mathrm{CP}(\mathrm{CA})$ & $220 \pm 10^{\mathrm{a}}$ & $2.10 \pm 0.20^{\mathrm{ab}}$ & $15.3 \pm 1.3^{\mathrm{b}}$ & $76 \pm 7^{c}$ & $280 \pm 30^{\mathrm{a}}$ \\
\hline & $\mathrm{CP}(\mathrm{CA})-\mathrm{S}$ & $3.2 \pm 0.2^{\mathrm{c}}$ & $3.20 \pm 0.40^{\mathrm{a}}$ & $11.3 \pm 1.4^{\mathrm{c}}$ & $110 \pm 10^{a}$ & $5 \pm 1^{\mathrm{c}}$ \\
\hline \multirow[t]{2}{*}{ Isooctane } & $\mathrm{CP}(\mathrm{CA})$ & $9.1 \pm 2.0^{\mathrm{b}}$ & $2.41 \pm 0.01^{\mathrm{b}}$ & $17.2 \pm 0.1^{\mathrm{a}}$ & $86 \pm 1^{\mathrm{b}}$ & $6 \pm 1^{c}$ \\
\hline & $\mathrm{CP}(\mathrm{CA})-\mathrm{S}$ & $0.6 \pm 0.2^{\mathrm{ef}}$ & $1.87 \pm 0.40^{c}$ & $6.7 \pm 1.4^{\mathrm{d}}$ & $70 \pm 10^{c}$ & $2 \pm 1^{\mathrm{d}}$ \\
\hline
\end{tabular}

a-f: Different superscripts within the same column indicate significant differences among tests $(\mathrm{p}<0.05)$. 

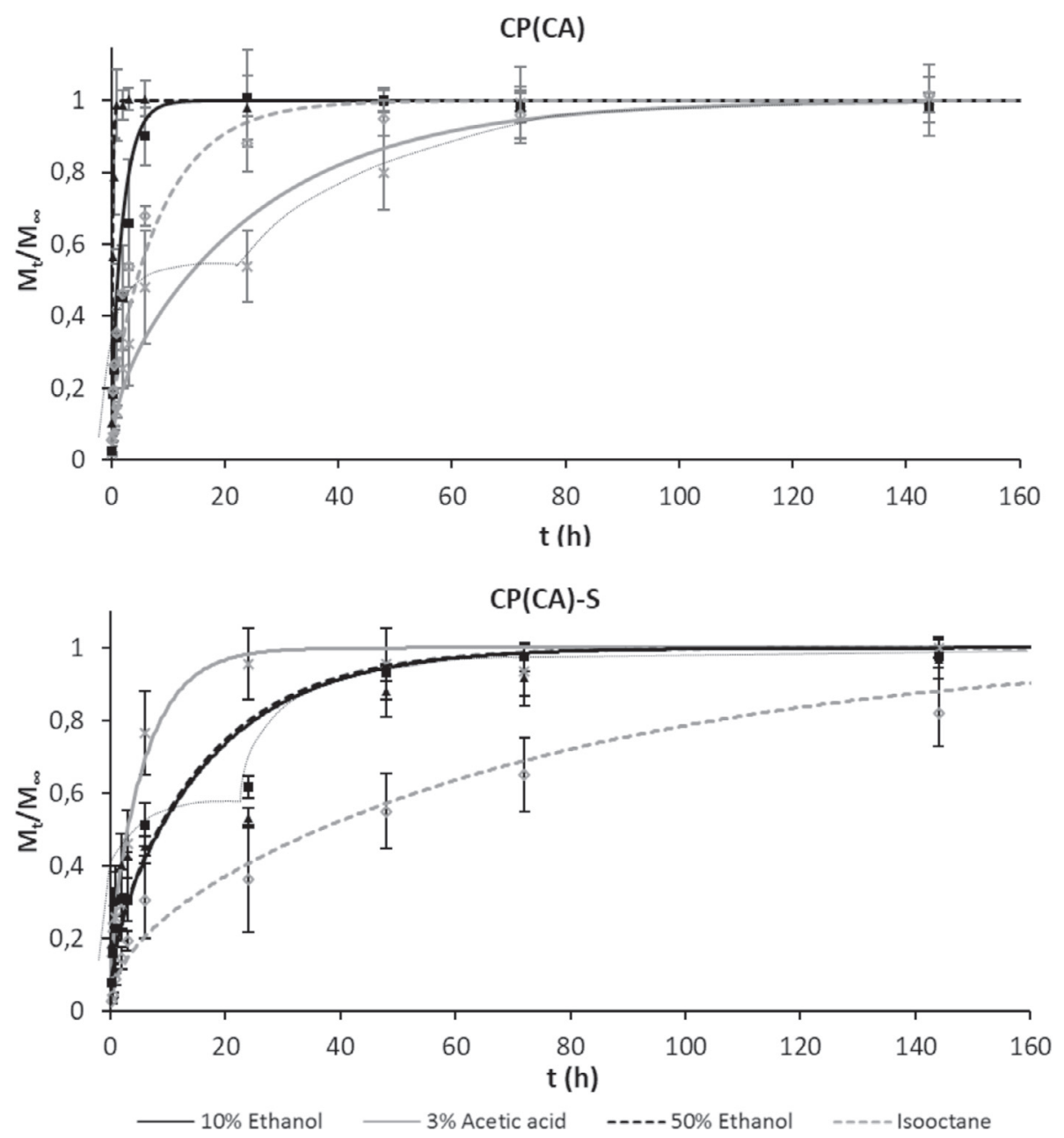

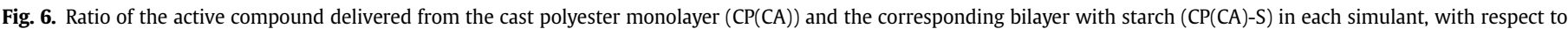

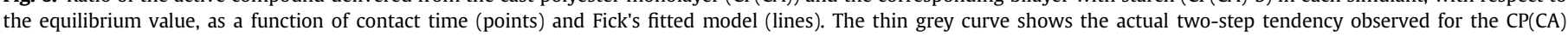
monolayer in $3 \%$ acetic acid and the $\mathrm{CP}(\mathrm{A})$-S bilayer in 10 or $50 \%$ ethanol.

stretchable when obtained by casting, although carvacrol incorporation into cast films greatly enhanced their extensibility, reducing the stiffness and water vapour permeability. The incorporation of carvacrol by spraying between the polyester and starch sheets was not effective at retaining the compound in the bilayers, mainly due to the radial flow promoted by the compound (especially in the starch layer) during thermocompression, which dragged a large proportion of the active to the film's edge. In contrast, the incorporation of carvacrol into cast polyester blend films, and the subsequent formation of bilayers with the starch sheets by means of thermo-compression, was highly effective at providing the practically total retention of carvacrol in both mono and bilayers. These active bilayers not only exhibited highly improved tensile and water vapour barrier capacity with respect to the starch monolayer $(87 \%$ reduction in WVP, $840 \%$ increase in elastic modulus) but also antibacterial properties against L. innocua and E. coli from both contact sides (polyester or starch) of the bilayer, depending on the internal diffusion of carvacrol through the bilayer and the adequate release of the compound into the culture medium. Then, cast PLA-PHBV blend films can be used as carriers of carvacrol for the purposes of obtaining well-adhered bilayers films with starch by means of thermocompression, with adequate tensile and barrier properties and antibacterial activity due to the good retention of the active during the film processing and its adequate release into food systems of differing polarities.

\section{References}

Acosta, S., Jiménez, A., Cháfer, M., González-Martínez, C., \& Chiralt, A. (2015). Physical properties and stability of starch-gelatin based films as affected by the addition of esters of fatty acids. Food Hydrocolloids, 49, 135-143.

Ahmed, J., Mulla, M. Z., \& Arfat, Y. A. (2016). Thermo-mechanical, structural characterization and antibacterial performance of solvent casted polylactide/cinnamon oil composite films. Food Control, 69, 196-204.

Armentano, I., Fortunati, E., Burgos, N., Dominici, F., Luzi, F., Fiori, S., et al. (2015a). Bio-based PLA_PHB plasticized blend films: Processing and structural characterization. LWT-Food Science and Technology, 64(2), 980-988.

Armentano, I., Fortunati, E., Burgos, N., Dominici, F., Luzi, F., Fiori, S., et al. (2015b). Processing and characterization of plasticized PLA/PHB blends for biodegradable multiphase systems. Express Polymer Letters, 9(7).

Arrieta, M. P., Fortunati, E., Dominici, F., Rayón, E., López, J., \& Kenny, J. M. (2014b). PLA-PHB/cellulose based films: Mechanical, barrier and disintegration properties. Polymer Degradation and Stability, 107, 139-149.

Arrieta, M. P., López, J., Ferrándiz, S., \& Peltzer, M. A. (2013). Characterization of PLAlimonene blends for food packaging applications. Polymer Testing, 32(4), $760-768$.

Arrieta, M. P., López, J., Hernández, A., \& Rayón, E. (2014c). Ternary PLA-PHB-Limonene blends intended for biodegradable food packaging applications. European Polymer Journal, 50, 255-270.

Arrieta, M. P., Samper, M. D., López, J., \& Jiménez, A. (2014a). Combined effect of poly (hydroxybutyrate) and plasticizers on polylactic acid properties for film intended for food packaging. Journal of Polymers and the Environment, 22(4), 460-470.

Auras, R., Harte, B., \& Selke, S. (2004). An overview of polylactides as packaging 
materials. Macromolecular Bioscience, 4(9), 835-864.

Avérous, L. (2004). Biodegradable multiphase systems based on plasticized starch: A review. Journal of Macromolecular Science: Part C: Polymer Reviews, 44(3), $231-274$

Babili, F. E., Bouajila, J., Souchard, J. P., Bertrand, C., Bellvert, F., Fouraste, I., et al. (2011). Oregano: Chemical analysis and evaluation of its antimalarial, antioxidant, and cytotoxic activities. Journal of Food Science, 76(3).

Benavides, S., Villalobos-Carvajal, R., \& Reyes, J. E. (2012). Physical, mechanical and antibacterial properties of alginate film: Effect of the crosslinking degree and oregano essential oil concentration. Journal of Food Engineering, 110(2), $232-239$.

Burt, S. (2004). Essential oils: Their antibacterial properties and potential applications in foods-a review. International Journal of Food Microbiology, 94(3), $223-253$.

Byun, Y., Kim, Y. T., \& Whiteside, S. (2010). Characterization of an antioxidant polylactic acid (PLA) film prepared with $\alpha$-tocopherol, BHT and polyethylene glycol using film cast extruder. Journal of Food Engineering, 100(2), 239-244.

Chen, G. X., Hao, G. J., Guo, T. Y., Song, M. D., \& Zhang, B. H. (2002). Structure and mechanical properties of poly (3-hydroxybutyrate-co-3hydroxyvalerate)(PHBV)/clay nanocomposites. Journal of Materials Science Letters, 21(20), 1587-1589.

Corre, Y. M., Bruzaud, S., Audic, J. L., \& Grohens, Y. (2012). Morphology and functional properties of commercial polyhydroxyalkanoates: A comprehensive and comparative study. Polymer Testing, 31(2), 226-235.

Courgneau, C., Domenek, S., Lebossé, R., Guinault, A., Avérous, L., \& Ducruet, V. (2012). Effect of crystallization on barrier properties of formulated polylactide. Polymer International, 61(2), 180-189.

Crank, J. (1975). Diffusion in a cylinder. The Mathematics of Diffusion, 69-88.

Del Nobile, M. A., Conte, A., Incoronato, A. L., \& Panza, O. (2008). Antimicrobial efficacy and release kinetics of thymol from zein films. Journal of Food Engineering, 89(1), 57-63.

Fakhouri, F. M., Costa, D., Yamashita, F., Martelli, S. M., Jesus, R. C., Alganer, K., et al. (2013). Comparative study of processing methods for starch/gelatin films. Carbohydrate Polymers, 95(2), 681-689.

Ferreira, B. M. P., Zavaglia, C. A. C., \& Duek, E. A. R. (2002). Films of PLLA/PHBV: Thermal, morphological, and mechanical characterization. Journal of Applied Polymer Science, 86(11), 2898-2906.

Fratianni, F., De Martino, L., Melone, A., De Feo, V., Coppola, R., \& Nazzaro, F. (2010). Preservation of chicken breast meat treated with thyme and balm essential oils. Journal of Food Science, 75(8).

Friedman, M., Henika, P. R., Levin, C. E., \& Mandrell, R. E. (2004). Antibacterial activities of plant essential oils and their components against Escherichia coli 0157: H7 and Salmonella enterica in apple juice. Journal of Agricultural and Food Chemistry, 52(19), 6042-6048.

Furukawa, T., Sato, H., Murakami, R., Zhang, J., Duan, Y. X., Noda, I., et al. (2005). Structure, dispersibility, and crystallinity of poly (hydroxybutyrate)/poly (Llactic acid) blends studied by FT-IR microspectroscopy and differential scanning calorimetry. Macromolecules, 38(15), 6445-6454.

Gerard, T., \& Budtova, T. (2012). Morphology and molten-state rheology of polylactide and polyhydroxyalkanoate blends. European Polymer Journal, 48(6) $1110-1117$.

Gérard, T., Budtova, T., Podshivalov, A., \& Bronnikov, S. (2014). Polylactide/poly (hydroxybutyrate-co-hydroxyvalerate) blends: Morphology and mechanical properties. Express Polymer Letters, 8(8), 609-617.

González, A., \& Igarzabal, C. I. A. (2013). Soy protein-Poly (lactic acid) bilayer films as biodegradable material for active food packaging. Food Hydrocolloids, 33(2), 289-296.

Irissin-Mangata, J., Boutevin, B., \& Bauduin, G. (1999). Bilayer films composed of wheat gluten and functionalized polyethylene: Permeability and other physical properties. Polymer Bulletin, 43(4-5), 441-448.

Jost, V., \& Kopitzky, R. (2015). Blending of polyhydroxybutyrate-co-valerate with polylactic acid for packaging applications-reflections on miscibility and effects on the mechanical and barrier properties. Chemical and Biochemical Engineering Quarterly, 29(2), 221-246.

Kalish, J. P., Aou, K., Yang, X., \& Hsu, S. L. (2011). Spectroscopic and thermal analyses of $\alpha^{\prime}$ and $\alpha$ crystalline forms of poly (1-lactic acid). Polymer, 52(3), 814-821.

Lim, G. O., Hong, Y. H., \& Song, K. B. (2010). Application of Gelidium corneum edible films containing carvacrol for ham packages. Journal of Food Science, 75(1).

Martelli, S. M., Sabirova, J., Fakhoury, F. M., Dyzma, A., De Meyer, B., \& Soetaert, W. (2012). Obtention and characterization of poly (3-hydroxybutyricacid-cohydroxyvaleric acid)/mcl-PHA based blends. LWT-Food Science and Technology, 47(2), 386-392.

Martucci, J. F., \& Ruseckaite, R. A. (2010). Three-layer sheets based on gelatin and poly (lactic acid), part 1: Preparation and properties. Journal of Applied Polymer Science, 118(5), 3102-3110.

Miguel, O., Egiburu, J. L., \& Iruin, J. J. (2001). Blends of bacterial poly (3hydroxybutyrate) with synthetic poly (3-hydroxybutyrate) and poly (epichlorohydrin): Transport properties of carbon dioxide and water vapour. Polymer, 42(3), 953-962

Modi, S., Koelling, K., \& Vodovotz, Y. (2012). Miscibility of poly (3-hydroxybutyrateco-3-hydroxyvalerate) with high molecular weight poly (lactic acid) blends determined by thermal analysis. Journal of Applied Polymer Science, 124(4), 3074-3081.

Mofokeng, J. P., \& Luyt, A. S. (2015). Dynamic mechanical properties of PLA/PHBV,
PLA/PCL, PHBV/PCL blends and their nanocomposites with $\mathrm{TiO}_{2}$ as nanofiller. Thermochimica Acta, 613, 41-53.

Moreno, O., Díaz, R., Atarés, L., \& Chiralt, A. (2016). Influence of the processing method and antimicrobial agents on properties of starch-gelatin biodegradable films. Polymer International, 65(8), 905-914.

Muller, J., González-Martínez, C., \& Chiralt, A. (2017a). Poly (lactic) acid (PLA) and starch bilayer films, containing cinnamaldehyde, obtained by compression moulding. European Polymer Journal, 95, 56-70.

Muller, J., González-Martínez, C., \& Chiralt, A. (2017b). Combination of poly (lactic) acid and starch for biodegradable food packaging. Materials, 10(8), 952.

Narayanan, A., \& Ramana, K. V. (2013). Synergized antimicrobial activity of eugeno incorporated polyhydroxybutyrate films against food spoilage microorganisms in conjunction with pediocin. Applied Biochemistry and Biotechnology, 170(6), 1379-1388.

Nilsuwan, K., Benjakul, S., \& Prodpran, T. (2017). Physical/thermal properties and heat seal ability of bilayer films based on fish gelatin and poly (lactic acid). Food Hydrocolloids, 77, 248-256.

Ortega-Toro, R., Morey, I., Talens, P., \& Chiralt, A. (2015). Active bilayer films of thermoplastic starch and polycaprolactone obtained by compression molding. Carbohydrate Polymers, 127, 282-290.

Ortega-Toro, R., Muñoz, A., Talens, P., \& Chiralt, A. (2016). Improvement of properties of glycerol plasticized starch films by blending with a low ratio of polycaprolactone and/or polyethylene glycol. Food Hydrocolloids, 56, 9-19.

Peleg, M. (1988). An empirical model for the description of moisture sorption curves. Journal of Food Science, 53(4), 1216-1217.

Petchwattana, N., \& Naknaen, P. (2015). Utilization of thymol as an antimicrobial agent for biodegradable poly (butylene succinate). Materials Chemistry and Physics, 163, 369-375.

Ramos, M., Jiménez, A., Peltzer, M., \& Garrigós, M. C. (2012). Characterization and antimicrobial activity studies of polypropylene films with carvacrol and thymol for active packaging. Journal of Food Engineering, 109(3), 513-519.

Requena, R., Jiménez, A., Vargas, M., \& Chiralt, A. (2016a). Poly [(3hydroxybutyrate)-co-(3-hydroxyvalerate)] active bilayer films obtained by compression moulding and applying essential oils at the interface. Polymer International, 65(8), 883-891.

Requena, R., Jiménez, A., Vargas, M., \& Chiralt, A. (2016b). Effect of plasticizers on thermal and physical properties of compression-moulded poly [(3hydroxybutyrate)-co-(3-hydroxyvalerate)] films. Polymer Testing, 56, 45-53.

Requena, R., Vargas, M., Atarés, L., \& Chiralt, A. (2017a). Biopolymers carrying essential oils, or their compounds, for food antimicrobial packaging. Current Organic Chemistry, 21, 1-16.

Requena, R., Vargas, M., \& Chiralt, A. (2017b). Release kinetics of carvacrol and eugenol from poly (hydroxybutyrate-co-hydroxyvalerate) (PHBV) films for food packaging applications. European Polymer Journal, 92, 185-193.

Rojas-Graü, M. A., Avena-Bustillos, R. J., Olsen, C., Friedman, M., Henika, P. R. Martín-Belloso, O., et al. (2007). Effects of plant essential oils and oil compounds on mechanical, barrier and antimicrobial properties of alginate-apple puree edible films. Journal of Food Engineering, 81(3), 634-641.

Sánchez-González, L., Cháfer, M., González-Martínez, C., Chiralt, A., \& Desobry, S (2011). Study of the release of limonene present in chitosan films enriched with bergamot oil in food simulants. Journal of Food Engineering, 105(1), 138-143.

Sanyang, M. L., Sapuan, S. M., Jawaid, M., Ishak, M. R., \& Sahari, J. (2016). Development and characterization of sugar palm starch and poly (lactic acid) bilayer films. Carbohydrate Polymers, 146, 36-45.

Savenkova, L., Gercberga, Z., Bibers, I., \& Kalnin, M. (2000). Effect of 3-hydroxy valerate content on some physical and mechanical properties of polyhydroxyalkanoates produced by Azotobacter chroococcum. Process Biochemistry, 36(5), 445-450.

Scaffaro, R., Sutera, F., \& Botta, L. (2018). Biopolymeric bilayer films produced by coextrusion film blowing. Polymer Testing, 65, 35-43.

Sheth, M., Kumar, R. A., Davé, V., Gross, R. A., \& McCarthy, S. P. (1997). Biodegradable polymer blends of poly (lactic acid) and poly (ethylene glycol). Journal of Applied Polymer Science, 66(8), 1495-1505.

Siracusa, V., Rocculi, P., Romani, S., \& Dalla Rosa, M. (2008). Biodegradable polymers for food packaging: A review. Trends in Food Science \& Technology, 19(12), 634-643.

Souza, A. C., Goto, G. E. O., Mainardi, J. A., Coelho, A. C. V., \& Tadini, C. C. (2013) Cassava starch composite films incorporated with cinnamon essential oil: Antimicrobial activity, microstructure, mechanical and barrier properties. LWTFood Science and Technology, 54(2), 346-352.

Tawakkal, I. S., Cran, M. J., \& Bigger, S. W. (2016). Release of thymol from poly (lactic acid)-based antimicrobial films containing kenaf fibres as natural filler. LWTFood Science and Technology, 66, 629-637.

Versino, F., López, O. V., \& García, M. A. (2015). Sustainable use of cassava (Manihot esculenta) roots as raw material for biocomposites development. Industria Crops and Products, 65, 79-89.

Woranuch, S., \& Yoksan, R. (2013). Eugenol-loaded chitosan nanoparticles: II. Application in bio-based plastics for active packaging. Carbohydrate Polymers 96(2), 586-592.

Xu, J., Zhou, F., Ji, B. P., Pei, R. S., \& Xu, N. (2008). The antibacterial mechanism of carvacrol and thymol against Escherichia coli. Letters in Applied Microbiology, 47(3), 174-179.

Ye, H., Shen, S., Xu, J., Lin, S., Yuan, Y., \& Jones, G. S. (2013). Synergistic interactions of cinnamaldehyde in combination with carvacrol against food-borne bacteria. 
Food Control, 34(2), 619-623.

Zhang, M., \& Thomas, N. L. (2011). Blending polylactic acid with polyhydroxybutyrate: The effect on thermal, mechanical, and biodegradation properties. Advances in Polymer Technology, 30(2), 67-79.
Zhao, H., Cui, Z., Sun, X., Turng, L. S., \& Peng, X. (2013). Morphology and properties of injection molded solid and microcellular polylactic acid/polyhydroxybutyratevalerate (PLA/PHBV) blends. Industrial \& Engineering Chemistry Research, 52(7), 2569-2581. 